\title{
Partial Class Behavior and Nasal Place Assimilation*
}

\author{
Jaye Padgett \\ University of California, Santa Cruz
}

\section{Introduction}

This paper has two goals. The first is to pursue and further motivate some ideas developed in Padgett (1995a) on the status of the notion feature class in phonological theory. The second is to explore the phenomenon of place assimilation. These goals are brought together in an exploration of facts involving nasal place assimilation to complex segments: assimilation in such cases is often partial in the sense that only one articulator of the complex segment spreads under a general process of place assimilation. As we will see, partial assimilation of this sort bears in an important way on our understanding of feature classes.

The notion 'feature class' makes general reference to familiar categories like Place, Laryngeal, VPlace, and so on, classifications of features instantiated most notably in work within Feature Geometry theory (henceforth FG, Clements 1985). FG seeks to explain recurrent copatternings of features according to these categories, by means of the representational device class node: constraints can target a node Place (for example), and thereby indirectly affect all dependent features as a group. Padgett (1995a) explores an alternative understanding of feature classes, called Feature Class Theory (FCT), in which classes are defined instead as sets of features (having no tree-theoretic instantiation). Features pattern into sets according to properties shared by their members-place-hood, laryngeality, and so on. Constraints can make mention of these sets, so that the central insight of FG is preserved, but they thereby target individually the member features having the right properties.

FCT finds key motivation in a certain brand of partial class behavior first noted by Sagey (1987) under the rubric 'non-constituent' behavior. The phenomenon is illustrated below with an example involving Turkish and the feature class Color $=$ \{back, round $\}$. The example and argument come from Padgett (1995a); on the class Color see also Odden (1991) and Selkirk (1991a). Turkish vowel harmony amounts to an imperative that this class of features span a word, as shown in (1)a. (For the facts of Turkish vowel harmony and a classical autosegmental analysis see especially Clements and Sezer 1982.) However, harmony cannot establish a link between [round] and a non-high vowel, due to an independent segmental markedness condition disfavoring such linkage. Resulting from this prohibition are instances of partial class behavior, in which only

* For very helpful discussion leading to improvements of this paper I would like to thank Donka Farkas, Junko Itô, Ewan Klein, Linda Lombardi, Armin Mester, Geoff Pullum, participants at the Arizona Phonology Conference, and the members of my Spring 1995 phonology seminar at UCSC. The paper also benefitted from discussion during talks presented at UC Berkeley, Stanford University and the Current Trends in Phonology Conference in Royaumont, France. I am especially indebted to Jill Beckman and Maire Ni Chiosáin for a close reading of the first draft. 
one member of the targeted class Color-namely [back]-conforms to the harmony imperative, shown in (1)b. (- $b$ and $r$ are [-back] and [round] respectively.)

(1) Full (a) and partial (b) class behavior - Turkish and Color

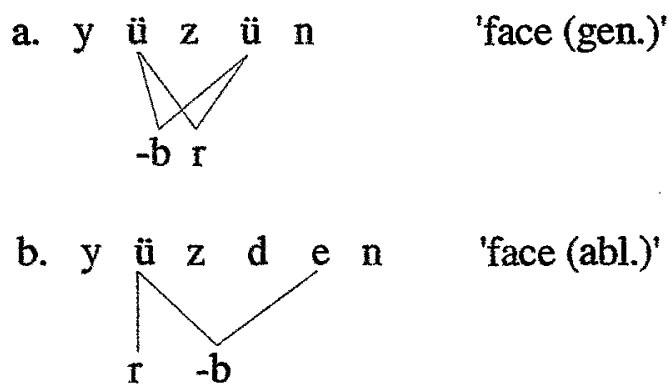

Such partial class behavior is surprising from the perspective of FG, because of the way that feature classes like Color are represented and understood. They are embodied as elements of a tree representation, the class nodes, upon which rules operate directly, affecting the relevant dependent features only indirectly. These nodes have always been interpreted to function in an allor-nothing fashion: if color harmony results from the linkage of a node Color, as in (2), then the invariant expectation has been that both [back] and [round] will be linked, or failing that, neither one will be linked (unless a separate rule is invoked). Such a theory makes no provision for the intermediate possibility of partial class behavior.

(2) Total class behavior in FG: *yüzdön or *yïzdAn (no harmony)

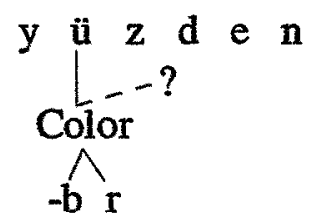

Apparently for this reason, the FG literature has failed to call on the robust evidence of Turkish and other (especially Altaic and Uralic) color harmonies as evidence for a class Color - though this class has ample precedent in phonological theory, and has been argued for within FG itself (Odden 1991). Though FG can be recast so as to accommodate partial class behavior, the required alteration essentially strips the class nodes of their function of capturing feature classes, and entails something like the FCT point of view, as we will see.

FCT therefore extends the explanatory role of the feature class idea to empirical areas otherwise untraversed. The case of color harmony outlined above is explored in detail in Padgett (1995a). The present paper instead concentrates on facts of nasal place assimilation by consonants (henceforth: NPA), and considers a range of partial assimilation data involving diverse complex segment types. The first goal of the paper, then, is to demonstrate the pervasiveness of partial class behavior with reference to another well-known phenomenon, NPA, and so further motivate FCT.

Exploration of this territory requires some reckoning with the facts of place assimilation very generally, and a theoretical discussion of this phenomenon forms the second goal of the 
paper. Foremost among the themes here is the important role given to the notion segmental release (McCawley 1967, Selkirk 1982, Steriade 1993a-b, 1994), seen here as a featural property that lends great prominence to a segment's other featural distinctions. Such prominence exerts its influence through release-sensitive faithfulness constraints; this builds on the more general idea of position- or prominence-sensitive faithfulness (Selkirk 1994, Beckman 1995). It emerges from these findings that positional categories like 'onset' and 'coda' are often only indirectly relevant to feature licensing, and hence assimilations, contrary to the prevalent view. Further, motivation is found for a feature spreading imperative in assimilations, a surprising fact from the perspective of accounts appealing solely to featural licensing in order to achieve multiple linkage of place.

This work is inspired by central tenets of Optimality Theory (henceforth OT, Prince and Smolensky 1993), calling in particular on those of constraint ranking and (minimal) violability. The representational issue aside, the central point of FCT is that constraints mentioning classes like Place and Laryngeal are gradiently violable, a claim that informs the upcoming account of partial class behavior. Such behavior ensues most commonly under the scenario $C>>$ CONSTRAINT(CLASS), where $\mathrm{C}$ is any constraint, CONSTRAINT(CLASS) is a constraint targeting any class of features, and the two constraints conflict for some proper subset of the set Class. In he case of Turkish above, $C$ prohibits the output of (non-initial) non-high round vowels, and JONSTRAINT(CLASS) is a constraint requiring harmony (treated as alignment in Padgett 1995a, and called ALIGN(COLOR)); these constraints conflict with respect to the feature [round] (a proper subset of Color) in forms where harmony would effect linkage of [round] to a non-high vowel. The harmony imperative is therefore violated - but not fully, since [back] conforms.

OT provides a theoretical context in which FCT is essentially necessitated. Once we cast an informed eye on traditional rule-specific stipulations, factoring them out by appeal to the interaction of independent constraints, we frequently find the scenario C > CONSTRAINT(CLASS) (understood as above) as a matter of course. In some cases this factoring will propel us to unify processes once thought of as separate, as when [back] and [round] harmonies are united in Color harmony (see Padgett 1995a). In all cases, including those explored below involving Place, the notion class node is reduced in content to mere feature class label, doing no real work in the theory. ${ }^{1}$

Section 2 below explicates the essential properties of FCT and argues for it on the basis of the partial NPA phenomenon. In section 3 we turn our attention to the task of finding a general account of place assimilations in OT. Section 4 provides empirical substance for uniting these separate expositional strands, briefly surveying a range of data involving partial NPA to various complex segment types, and analyzing a case from Gã, calling on ideas just developed.

${ }^{1}$ An interesting question then follows: do class nodes qua representational entities play any role in the theory, other than that of capturing feature class behavior? Assertions that they do are uncommon in the literature, though class nodes have been called on in order to explain facts of segment transparency and opacity, and to illuminate facts of place feature interaction more generally. See Padgett (1995a,b) for respective critical discussion. 


\section{Feature Class Theory}

\subsection{Capturing Feature Classes}

It is now a familiar observation that some phonological features pattern together recurrently in processes of assimilation, dissimilation, neutralization, and so on. Feature classes similar to Laryngeal and Place achieved a formal status within generative phonology first in the work of Dependency phonologists (Lass and Anderson 1975, Lass 1976, Anderson and Ewen 1987), and later most prominently in Feature Geometry theory (Clements 1985, cf. Mascaró 1983, Mohanan 1983). Within FG, the feature class promise is fulfilled by means of ontological entities known as class nodes, incorporated into a tree representation; these are directly targeted by phonological rules/constraints. The following FG representation, a pared-down adaptation from McCarthy (1988), serves to anchor the discussion.

(3) The classes Place and Laryngeal in FG

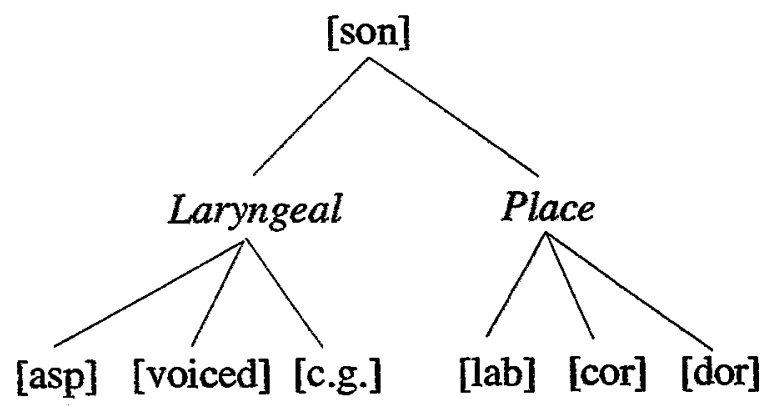

Class nodes in FG (like those italicized above) are central to that theory, serving as key mediators of feature class behavior. Thus a rule demanding the spreading of Place is understood to target the relevant class node; entailments attributed to featural dependency ensure that the actual place features themselves will be affected at the same time. These latter features are therefore affected only indirectly. We will return to this fact and explore its significance in section 2.2 .

FCT is a less 'syntactic' and more 'semantic' approach to the feature class insight: terms like Place and Laryngeal stand for sets of features, as shown below. These sets have their basis in the properties that their members share: here, place-hood and laryngeality respectively. (For a precedent involving syntactic feature classes, see Gazdar et al. 1985:23.)

(4) The classes Place and Laryngeal in FCT

Place $\quad=_{\text {def }} \quad$ \{labial, coronal, dorsal...

Laryngeal $=_{\text {def }}$. $\{$ aspirated, voiced, constricted glottis $\}$ 
Naturally, constraints must be able to refer to these classes; FCT maintains the important feature class insight of FG. ${ }^{2}$ However, there are now no objects in the representation (class nodes) to mediate feature class behavior in the way seen in (2). By hypothesis we are reverting to a simplified structure most reminiscent of 'bottlebrush' theories (see Hayes 1990 on these theories). In the representation below, feature order is randomized to emphasize the point: classes are understood as sets of features that share the relevant property. The intuition we are developing is straightforward: constraints mention classes like Place and Laryngeal, but they thereby target, directly and individually, the features in the respective extensions of these classes, defined in (4).

FCT representation

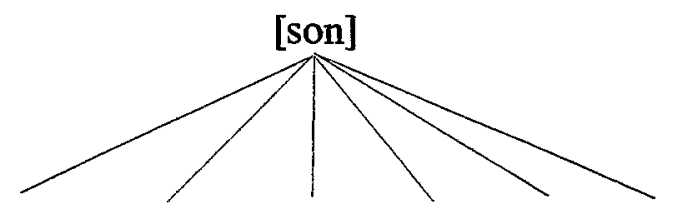

[lab] [voiced] [c.g.] [dors] [cor] [asp]

For the sake of discussion, let us consider a provisional constraint demanding NPA, in the formulation given below. This formulation is a temporary convenience; in section 3 we will inquire more seriously into the nature of the phenomenon.

(6) NPA: In every sequence NC, every Place linked to $\mathrm{C}$ is linked to N, and vice versa

This constraint must be understood to bear on the feature [labial] in the representation in (7), by virtue of this feature's status as a place feature. More generally, it must require double linkage of every individual feature of the set Place in the right (NC) configuration.

[labial] targeted as a Place feature

$$
\begin{aligned}
& \text { [+son] [-son] } \\
& 111 \\
& \text { [+nas] [labial] }
\end{aligned}
$$

An understanding of feature class behavior more or less along these lines is advocated in Selkirk (1991a,b) and Padgett (1991); Hayes (1990) represents a move in the same direction, maintaining the class nodes of FG while essentially motivating individual feature behavior in various 'diphthongization paradoxes'. Sagey (1987) argues for a limited use of individual feature spreading in order to capture class behavior, viewing it as a marked option within FG; Halle (1995) picks up Sagey's argument (though cf. Ní Chiosáin 1995), but advocates individual feature targeting as the only possibility in the theory, as we do here. Differences among these various proposals for individual feature targetting are discussed in the next section.

2 The classes are assumed to be fixed and universal as well, in the usual way. The make-up of Laryngeal and especially Place in (4) is obviously not intended to be either exhaustive or definitively accurate; these substantive issues cross-cut the choice of theory. 
In order to ensure class behavior as informally illustrated above, we simply capitalize on the postulated sets rather than on postulated nodes. Terms like Place, Laryngeal and Color are convenient stand-ins for these sets in constraint formulations. However, a look at various possible constraint types reveals a fact worth keeping in mind: different constraints will quantify over these sets in different ways. Thus the intent of our constraint NPA is to quantify universally over the place features, and a rendition with the relevant portion formalized might be the following (where $x$ ranges over features, and $F(S)$ means 'feature $F$ is contained in segment $S$ ', i.e., dominated by the same Root node $=[$ son $]$ feature):

(8) NPA redux: For every sequence $\mathrm{NC}, \forall_{\mathrm{x}}, x \in$ Place, $x(\mathrm{~N}) \Leftrightarrow x(\mathrm{C})$

It should still be clear that this constraint is satisfied by the representation in (7). We will further explore its interpretation momentarily. First, to see how a different quantificational force can arise from another constraint, consider the formulation below of a constraint banning placeless segments, again with the portion of interest formalized below it (see Itô and Mester 1993, Lombardi 1995a, among others, on such a constraint).

(9) HAVEPLACE: Every segment must have some Place

For every segment $\mathrm{S}, \exists_{\mathrm{x}}, x \in$ Place, $x(\mathrm{~S})$

This constraint requires existential quantification over the feature class. This is the result we want; we do not intend that every Root must dominate all places, for instance. One need not endorse the particular constraints just considered in order to see the point: constraints will differ in the sort of quantificational restrictions they place on their variables. Terms like Place and Laryngeal in an informally stated constraint actually stand in conveniently for these variables and the relevant sets. ${ }^{3}$

Returning to our provisional NPA, let us run it by a few more representations for completeness. The following summary rates the success of several representations with respect to this constraint, and provides explanatory commentary. The representations have been minimized: L,C,D stand for [labial], [coronal] and [dorsal] respectively.

(10) How NPA rates representations

Representation NPA Commentary

a. paggur

$\checkmark$

One NC sequence, one place, doubly linked.

D

${ }^{3}$ Padgett (1995a) attempts a general definition of CONSTRAINT(CLASS) that seems to wrongly usurp the freedom of a constraint to choose its own quantifiers and variables in this way. The discussion here is meant to supersede that attempt. 
b. mpa g g r

$\begin{array}{ll}V & \text { V } \\ \text { L } & \text { D }\end{array}$

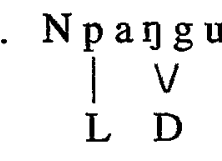

d.<smiles>[2H][Ga][Ba][Ba]</smiles>

e.

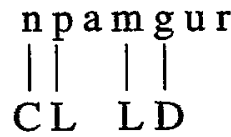

f. $p$ a g r
In every NC sequence, every place is doubly linked.

In one NC sequence, one place is not doubly linked. (HAVEPLACE is also violated.)

In one NC sequence, two places are not doubly linked. (Note the biconditional in (8).)

In two NC sequences, two places are not doubly linked.

Constraint vacuously satisfied.

As can be seen from the violations marked and the commentary, NPA can be violated more than once in a representation. The constraint is treated as gradient-it is worse to have four place features in the relevant configuration fail to be doubly linked than to have only two place features fail in this way, (10)d vs. (10)e, and so on. That is, every $x, x \in$ Place is not interpreted in the most straightforward truth-conditional way, such that one, or many, failures translates simply as 'false'. Gradience of this sort is now familiar in the OT literature; for general discussion see Prince and Smolensky (1993), and McCarthy and Prince (1993a). Gradience will be important to our understanding of partial class behavior later.

Though we will soon revise our understanding of nasal place assimilation, the discussion here illustrates very generally how any constraint mentioning a feature class is to be constructed and understood. Before we move on, it is worth making another point concerning FCT. Like FG, FCT postulates partitionings of sets of features; thus, the classes Place and Laryngeal, for example, do not intersect. This move addresses an empirical claim that no feature could belong to both classes; if correct, a formal statement to this effect is required in either FG or FCT. ${ }^{4}$ As for substantive questions like why non-intersection seems (at least largely) correct, or why the sets are divided up precisely as they are and not some other way, the general answer is again theoryneutral: feature classes seem to have their basis in phonetic parameters, whether articulatory or acoustic. (See for example Clements 1985, Sagey 1986, McCarthy 1988, Padgett 1991, 1995c and Zsiga 1993 on this.) Thus while the extension of the set Place is a mere list \{labial, coronal, dorsal..., , the intension is revealed by the phonetic term Place itself. Presumably a fuller understanding of this basis will shed some light on the issues raised here.

${ }^{4}$ It is a common perception that FG makes this partitioning seem more natural; we are presumably not allowed to link [labial], say, to both Place and Laryngeal in a tree. The implicit tree-theoretic notion here is the Single Mother Condition. In truth, such a condition must either be stipulated or derived in FG. 


\subsection{Partial Class Behavior}

Suppose we compare accounts within FCT and FG for a straightforward case of NPA, such as that of Spanish (see especially Harris 1984 for an analysis and discussion of the Spanish facts). NPA obtains within words in Spanish, across all places, giving forms like the following:

(11) NPA in Spanish

$\begin{array}{llll}\text { sie[m]pre } & \text { 'always' } & \text { pre[n]sa } & \text { 'press' } \\ \text { á[m]fora } & \text { 'amphora' } & \text { co[n]cha } & \text { 'shell' } \\ \text { a[n]dar } & \text { 'to walk' } & \text { á[n]gel } & \text { 'angel' }\end{array}$

Assimilation involves at the least all of the major articulator features required for Spanish, [labial], [coronal] and [dorsal], and so the generalization is over the category Place. In many instances, including this one, FCT and FG will be empirically indistinguishable. The former will target every member of a set of features, as outlined in the last section; the result will be linkage of any such feature found in a particular representation, as shown in (12)a. FG instead targets a node Place in the representation, demanding linkage of this entity, (12)b; the logic of dependency entails that any features dependent on Place will be interpreted as extending over both segments now also. ${ }^{5}$

(12) Place assimilation in FCT and FG - two representations of [nt]

a. $\begin{array}{ccc}1+\text { son }] & {[- \text {-son }]} \\ 1 & 1 & 1 \\ {[+ \text { nas }]} & {[\text { cor }]}\end{array}$
b.

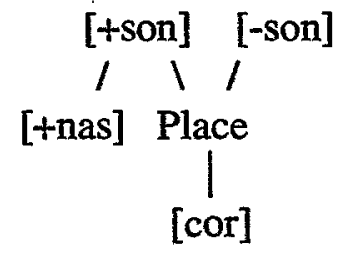

One benefit of FG noted by Sagey (1986) involves its straightforward handling of assimilation to complex segments like [gb] of Kpelle. Like Spanish, Kpelle evinces NPA across all places, e.g., [m]bolu 'my back', [n]dia 'my tattoo', [n]gos 'my foot' (Welmers 1962). Tones are omitted from the cited forms; the assimilating nasal is syllabic. As is true in many West African languages, assimilation to [gb] yields [ $[\hat{m} \mathrm{gb}$ ], a homorganic sequence of a doubly articulated nasal followed by the doubly articulated stop, e.g., [nm]gbin'myself. If [gb] is a single segment represented as in (13)a, then linkage of the node Place will entail this fact without further ado, (13)b.

${ }^{5}$ This logic of dependency fails us when confronted with feature class generalizations involving phenomena other than assimilation or positional neutralization, providing arguments for FCT considered in Padgett (1995b). These include OCP effects and constraints like HAVEPLACE seen earlier. 
(13) Assimilation to complex segment in FG
a. [-son]
b. [tson] [-son]
Place
Place
11
11
[lab] [dor]
[lab] [dor]

FCT retains this benefit, if NPA (however conceived) requires linkage of all members of Place in the NC configuration, as suggested in our provisional constraint NPA above. In this case the relevant features are targeted directly, by virtue of their status as place features, without the mediation of a mother node:

(14) Individual feature targeting via the feature class Place in FCT

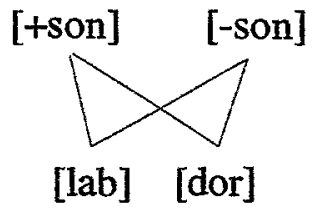

However, another outcome of NPA before complex segments is observed in some languages. Deferring full discussion of the facts to section 4, we simply note the result here to pursue the point: assimilation to [gb] can give simple [ $\mathrm{\eta}]$, as in Gã, another language of West Africa. This difference is contrastive within the language: NPA to labiovelars within morphemes is total in Gã, e.g., [nm]kpai 'libation'. Across a morpheme boundary, in contrast, we see the partial assimilation, e.g., [n]-kpai 'my cheeks' (Kropp 1966, Kotey 1974, Ryder 1987). Here, as in Kpelle, the assimilating nasal is syllabic. The outcome [ngb] is an example of partial class behavior, shown below.

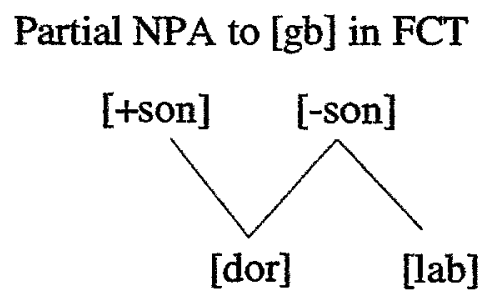

Assimilation is partial here in much the same way it is partial in the case of the English prefix in-, which gives $i[m]$ portant and $i[n] d e l i b l e$ etc., but fails to assimilate before velars, as in $i[n]$ competent (careful speech). In both cases NPA requires NC double linkage of every place feature in an NC configuration. This constraint is violated in English by forms such as incompetent, due to a higher ranking markedness prohibition against $\eta$. In Gã we similarly see a violation of the constraint, due again to reasons of markedness-a ban on doubly articulated $\mathrm{mm}$ (see below). In neither language is NPA violated completely or wantonly; in fact it is otherwise obeyed. However, while FG has no problem with partial class behavior like that of English, that of Gã causes trouble. The reason is simple: in Gã one need not look across forms or even different $\mathrm{NC}$ clusters to see that assimilation is partial. Rather we find partial class behavior arising within a 
single NC cluster in (15): some, but not all, of the Place features of $g b$ spread. Partial class behavior in such cases finds no home in FG (see also Padgett 1995a on this point). Because in FG constraints target actual place features only indirectly, via a mother Place node and dependency entailments, we essentially expect one of two outcomes: either all place features will assimilate, or, if assimilation is impossible, no features will assimilate. These outcomes are contrasted below.

(16) No partial class behavior in FG - constraints/rules target node Place
a. [tson] [-son]
b. [tson] [-son]
Place $\quad=$ nmgb
Place $\quad=\mathrm{Ngb}$
11
11
Lab Dor
Lab Dor

In contrast, a central claim of FCT is that constraints mentioning feature classes are gradiently violable. FCT makes no formal distinction between the English and Gã cases, allowing their similarity to emerge naturally. The tableau in (17) anticipates the fuller discussion in section 4 . Assuming that the higher-ranked constraint ruling out the doubly articulated nasal is one of segmental markedness, called *COMPSEG ('no complex segments'), candidate (17)a is eliminated from consideration. Yet only this candidate fully satisfies NPA, and so this latter constraint must be violated. Violation is not total, however, as in candidate (17)c; this total failure of assimilation is unmotivated (and indeed will normally violate another important markedness constraint, HAVEPLACE). The optimal candidate violates NPA minimally, that is, only to the extent required by the posited ranking of constraints. This understanding of the facts therefore rests on two important tenets of Optimality Theory (Prince and Smolensky 1993): constraints are violable, and violation is minimal.

(17) NPA is gradiently violable

\begin{tabular}{|l||c|c|}
\hline $\mathbb{N}+\mathrm{gb} /$ & ${ }^{*}$ COMPSEG & NPA \\
\hline \hline a. $\mathrm{nmgb}$ & $* * !$ & \\
\hline b. $\mathrm{ngb}$ & $*$ & $*$ \\
\hline c. $\mathrm{Ngb}$ & $*$ & $* * !$ \\
\hline
\end{tabular}

It is easy to see that under the reverse ranking, NPA $\gg *$ COMPSEG, the fully assimilated candidate (17)a would emerge as optimal. The analysis therefore correctly predicts the existence of both full and partial assimilation, and does so with a minimum of assumptions: markedness constraints against complex and placeless segments are required by any theory, as is some account of NPA. Partial assimilation falls out for free, given the existence of constraint (re)ranking, the quite general means of language variation in OT.

The failure of FG resides in its understanding of the representational entity class node: this entity and its interpretation together transiate essentially into a hard, 'sour grapes' constraint: in 
effect, either assimilate all features (of some category), or assimilate none. It is worth emphasizing that it is this interpretation of the representation that is at the heart of the failure, rather than the representation itself considered in a theoretical vacuum, if such a thing is possible. Indeed, Halle (1995) argues for individual class feature spreading while retaining class nodes, see below. The argument here is against hard or 'sour grapes' feature class generalizations, in whatever guise, in favor of their soft understanding illustrated above. ${ }^{6}$ FG is indeed such a 'hard' theory. Presenting the facts of Kpelle, in which assimilation to labiovelars is total (see above), Sagey (1986:101) provides a telling quote: "Given the representation of $/ \mathrm{kp} / .$. there would be no way for place assimilation spreading the place node to spread just the dorsal, or just the labial, articulation." Clearly Sagey is not alone in this understanding of FG; in the wake of her important work, the relatively widespread phenomenon of just such partial assimilations has gone largely unnoticed (though see Ryder 1987); it is hard to avoid the conclusion that theoretical expectations have themselves constrained perception of the data. In fact, FG has failed to reveal some genuine feature class generalizations entirely, because of its promotion of hard feature class constraints (see the discussion of Color harmony in the introduction and in Padgett 1995a). These failings point up the two-edged nature of the strategy by which rules (and more generally our understanding of phonology) follow from (interpreted) representations themselves.

Some possible objections arise at this point. First, suppose FG is correct to regard feature class generalizations as categorical rather than gradiently violable. Perhaps NPA in Gã should be supplemented with another rule/constraint effecting linkage of the feature [dorsal] in just the context $N+g b$. This view might share one aspect of our account: regular NPA is not possible before labiovelars for reasons of markedness (though it turns out that some such languages allow underlying $/ \mathrm{mm} /$ to surface, so the generalization might elude some surface-true theories). Either [dorsal] assimilation follows as a 'repair' (Paradis 1988) to avoid the surfacing of a placeless segment, or else a rule/constraint of [dorsal] assimilation preempts NPA by the Elsewhere Condition (Kiparsky 1973, 1982, cf. Scobbie 1993). It is hard to see the appeal of such an approach over that advocated here. The activity of a constraint targeting [dorsal] must be separately postulated, having no formal connection to the more general constraint that targets a class Place, and so seems purely coincidental. As we saw above in contrast, a form like [igb] falls within the scope of a general NPA in the FCT account, given the interaction between this constraint and that of markedness. ${ }^{7}$

Consider instead an attempt within FG to embrace partial class behavior of this kind, by postulating the following principle guiding feature class generalizations:

\footnotetext{
${ }^{6}$ Some work in what is broadly called Unification-Based grammar dispenses altogether with the distinction between 'constraint' and 'representation'. In Scobbie (1991) for example (and cf. Bird 1995), [labial], [coronal] etc. have the status of values of a larger feature category Place, all embedded in a theory built on feature structures and their unification. This general paradigm favors constraints that are strictly speaking true of surface forms (and so not violable), and so seems to require the 'hard' understanding of feature class generalizations as well.

${ }^{7}$ As a separate issue, any theory must account for the spreading here of [dorsal] in particular, rather than [labial]; see section 4.
} 
To target a set of features Class,

a. Target the node Class; unless targeting this node will fail, in which case:

b. Target individually as many features dominated by node Class as possible

Whether understood processually or not, any resort strategy of this kind has the 'do this unless that in which case...' quality that Optimality Theory seeks to redress, and seems unappealing on the face of it. In fact, once we allow for (18)b, the theory has no place for (18)a: surely a constraint always targets as many features as possible. FG recast in this way is now an ungainly kin to FCT.

Finally, we might preserve the FG representation while abandoning its traditional interpretation, incorporating something in the spirit of (18)b into the theory, and dispensing with (18)a, as in Halle (1995), who builds on Sagey (1987). This view shares with FCT the assumption that feature class constraints target the relevant features directly and individually as a matter of course. The class nodes are now reduced in content to the status of feature class labels, having a function similar to that attributed to sets in FCT. The version of this theory suggested by Halle (1995) differs significantly from FCT, however. First, FCT is explicitly committed to the idea of gradient violability of constraints at the surface, and it is couched therefore within OT. Halle (1995) is instead cast within a framework employing ordered rules (as in Bromberger and Halle 1989), and the theoretical implications of the conflicts that inevitably arise between feature class constraints and other constraints are not explored. Halle's example of partial class behavior comes from Barra Gaelic, and tacitly calls on a ranking of the Line Crossing Prohibition over a rule requiring that vowel place features (classed as Place by Halle) spread. The analysis of Barra posited is not fully secure (see Ní Chiosáin 1995), but another example here serves to illustrate the idea. Vowel harmony in Turkish involves the class Color $=\{$ back, round $\}$, and may be treated as alignment of this class to prosodic word edges (see Padgett 1995a). The focus here is on the rightward spreading required of features in forms like that shown below. There is a contrast in Turkish stem-finally between plain and palatalized $l$, the latter bearing the feature [-back] and interacting with the spreading of this feature through harmony. In the word petrol ${ }^{t}-i \bar{i}$ 'petrol (acc.sg.)', the final suffixal vowel receives its [back] specification from the preceding palatalized lateral (cf. okul-u 'school', with a non-palatalized lateral); but it receives its [round] specification from the preceding vowel. (See Clements and Sezer for discussion.) Neither of the preceding vowels of this disharmonic form is capable of transmitting its [back] value (shown bolded below) to this suffixal vowel. This is a line crossing or locality issue in one sense-the [back] value of the lateral intervenes, and so blocks any such spreading. Thus rightward alignment of Color is violated by these [back] features. There is of course a faithfulness issue here as well: harmony is not fully obeyed at the expense of the loss of any [back] specifications. Obviously Color harmony seen as the linkage of a superordinate node bearing this name will encounter difficulty with examples like this one. 
(19) Partial class spreading due to line crossing/locality - Turkish

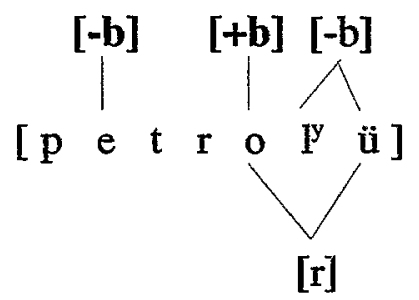

The analysis of Barra Gaelic due to Sagey and Halle is similar: it posits a rule spreading a class of place features from a vowel; [back] cannot spread, due to an intervening palatalized consonant, and spreads from this consonant instead. It is not clear, though, why line crossing (or the equivalent of faithfulness, protecting the disharmonic [back] values) prevails, or why a rule spreading vowel place features is allowed to succeed only partially, since no concrete views on constraint conflict are assumed. The general point here is that the predictions of FCT depend in part on the tenets of Optimality Theory; those of Halle (1995) will depend on how the relevant issues pan out in the framework in which that theory is embedded. ${ }^{8}$

\section{Place Assimilations}

The previous discussion assumes a provisional constraint NPA formulated in (6)/(8). This section delves into the issue of place assimilation more seriously (though necessarily leaving many issues untouched). To probe into assimilations is interesting not only in its own right, but because it can allow us to feel secure that points made above in favor of FCT carry over once we understand NPA better. This section makes several claims about the nature of place assimilation. First, crucial to an accurate characterization of environments of assimilation (and neutralization more generally) is the notion of segmental release, familiar most notably from the work of Steriade (1993a, 1994). It is the distinction between released and unreleased segments, rather than that between onset and coda, that determines the patterns, contrary to the prevalent view. This understanding of a general licensing issue will be implemented via release-sensitive faithfulness constraints, building on work motivating prominence-sensitive faithfulness (Selkirk 1994, Beckman 1995, Lombardi 1995a). Second, assimilations result in part from the workings of constraints directly requiring the spreading (or multiple linkage) of features, grounded in facts of perception and articulation. That is, facts of assimilation cannot be fully reduced to issues of licensing or prominence-based faithfulness alone. At least for the cases considered here, this spreading imperative does not itself incorporate any preferences about directionality, making it different from Alignment as standardly conceived (McCarthy and Prince 1993a). A theme tying the two major claims above together involves the appeal to phonetic bases in the formulation of constraints, an appeal that finds its motivation in the success of the constraints themselves. This

${ }^{8}$ For example, Halle posits a separate rule spreading [back] from the intervening consonant in Barra; [back] spreading from $l$ in Turkish instead falls out directly from a requirement of alignment of Color to the prosodic word edge, and so is unified with harmony. Whether this disadvantage is intrinsic to the framework assumed in Halle (1995) is unclear. As a separate matter, Halle (1995) allows individual feature targeting only for assimilations (p.20); FCT is intended to cover all feature class behavior, involving dissimilations, neutralizations, and so on as well. 
thinking follows many others making the phonetics-phonology connection in recent work, including most notably Archangeli and Pulleyblank (1994) and Steriade (1993b, 1995b).

Accounts of nasal place assimilation fall into two broad classes that have oddly coexisted. First, researchers in FG have often posited rules of roughly the form shown in (20)a (Padgett 1994, for example). The parameters of the rule depicted here are more perspicuously presented in a format adapted from Archangeli and Pulleyblank (1994), shown in (20)b. These statements together request that an association line (path) be inserted, leftwards, from the Place of a stop to a nasal segment. As Mohanan (1993) points out, each stipulation, to the extent that it represents a cross-linguistic tendency, provokes a corresponding question, as in (20)c.

(20) A rule of NPA

a.

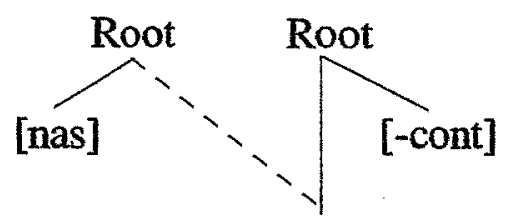

Place

b. Argument: Place

c. I. Why does Place frequently assimilate?

- Function: Insert

ii. Why does it assimilate?

Type: $\quad$ Path

iii. (Same as ii.)

Direction: L-R

Target: [nasal]

iv. Why is assimilation typically leftwards?

Arg.Conds: [-cont]

v. Why are nasals favored targets?

vi. Why are stops favored triggers?

These questions do not exhaust the potential list. Thus coronal consonants are favored targets of assimilation, and obstruents favored triggers as well. Padgett $(1991,1994)$ roots $(20) \mathrm{c}$-vi and other facts of NPA in the hypothesis that articulator features and oral stricture features like [continuant] and [consonantal] form a unit corresponding to the Gesture of Browman and Goldstein $(1986,1989)$, an idea we make brief reference to later. This section attempts to answer the remaining questions of (20)c. An important precursor to this task is Mohanan (1993), who formulates the major questions about place assimilation and proposes a range of solutions. The proposals here address fewer questions, though they attempt to develop in specific areas Mohanan's insight that recurrent tendencies in languages require explanation in terms of the interaction of simple, universal and phonetically grounded constraints. Recent ideas about place assimilation developed independently by Jun (1995) also have much in common with those here, including the appeal to prominence-based faithfulness (in a broad sense of the term) in order to capture asymmetries in assimilation. Jun extends this idea to areas not explored here, including asymmetries in target and trigger place.

The second major tack on NPA emerges from work on principles of syllabification due to Itô $(1986,1989)$, further developed into a general notion of licensing in Goldsmith (1990) and Itô and Mester (1993). Put most simply, this approach capitalizes on a hypothesized tension between 
two needs: first, Place must be licensed by a path to a syllable onset; second, segments must have some Place feature. The latter constraint we call HAVEPLACE here, formulated in (9) above. Call the former LICENSE for the moment. The tension between these constraints leads directly to place assimilation in these accounts, as made clear by the following constraint tableau. The reader should understand the third candidate as having doubly linked place.

A licensing account of NPA

\begin{tabular}{|c|c|c|}
\hline Input $=/ \mathrm{saNpo} /$ & HAVEPLACE & LICENSE \\
\hline a. saNpo & $* !$ & \\
\hline b. sanpo & & $* !$ \\
\hline c. sampo & & \\
\hline
\end{tabular}

The nasal segment in candidate (21)a is placeless and so violates HAVEPLACE. Candidate (21)b has a nasal segment, in a syllable coda, bearing its own place feature. Without a path from this place feature to a syllable onset, such a place feature is unlicensed. Double linking of Place as in (21)c manages to avoid both problems in one stroke. Assuming no higher ranked constraints that say otherwise, this candidate is necessarily optimal; as can be seen, no ranking of HAVEPLACE and LICENSE is required. Part of the great appeal of the licensing approach to place assimilation lies in the way it brings together facts of assimilation, neutralization, and syllable structure (see the references above, and Itô and Mester 1994, Lombardi 1995b for a development of the approach employing constraints of alignment). Below we modify this conception of licensing, recasting the issue as one involving prominence-sensitive faithfulness, only indirectly connected to prosodic factors like the onset versus coda distinction. However, the account preserves the insight that facts of assimilation and neutralization are tied together and have some connection to prosodic position.

\subsection{Licensing and Release}

It is useful to survey the syllable position environments under which NPA obtains crosslinguistically. All cases involve a nasal consonant strictly adjacent to the triggering consonant. The following examples illustrate the range of syllable affiliations found for target and trigger segments across languages (brackets indicate syllable boundaries).

(22) Syllable-related environments of NPA
a. $\mathrm{N}][\mathrm{C}$
Japanese, Spanish
d. $\mathrm{C}][\mathrm{N}]$
German haben habm
b. NC]
English kent, hampton
c. $[\mathrm{N}][\mathrm{C}$
Kpelle mbolu
e. $\mathbb{N} C$
Luganda lugaa][nda etc.

(22) $a-b$ have been the central focus of classical licensing accounts and should be familiar. We have already seen an example of the common pattern (22)c, involving a syllabic nasal, in Kpelle (section 2.2). The German (22)d represents an apparently less common reversal of Kpelle, with 
the syllabic nasal following the triggering consonant. Finally, the nasal is tautosyllabic and part of the onset in another common pattern (22)e; compensatory lengthening of the preceding vowel provides evidence for the bisegmental status of this NC sequence in Luganda (Clements 1986, and see the discussion in section 4).

The diversity of cases in (22) points up the difficulty of trying to determine a cross-linguistic generalization concerning the position in which nasal place is unlicensed (that is, in which assimilation must occur). The nasal is not always in the coda, for instance, but can occupy any syllable position - onset, nucleus or coda. The German case suggests that 'preconsonantal' is also not the right positional characterization. Apart from German, the many cases of word-final place neutralization, a phenomenon also in the domain of licensing theory, indicate the inadequacy of 'preconsonantal' for understanding unlicensed place (e.g., Spanish/Adam/ - [adan]). In fact, Goldsmith (1990), Mester and Itô (1993), Lombardi (1991) and Steriade (1995a), among others, seek generalizations in the complementary sphere, stating positive constraints of licensing; the right question for us, in this view, is where do nasals not assimilate?" The answer to this question is much more straightforward; a preliminary characterization is shown below (' $R$ ' is a liquid).

(23) Where nasals don't assimilate
a. [NV, [NR English ob][noxious (*obmoxious), Russian [mračno 'gloomy' (*račno, *nrac̆no), etc.
b. [CNV Russian dno 'bottom', kniga 'book' (*kgiga), etc.

This sketchy (but cross-linguistically representative) descriptive picture lightly masks one simple generalization: nasal place is preserved when the nasal precedes a tautosyllabic liquid or vocoid. This odd statement is strikingly similar to Lombardi's (1991) Laryngeal Constraint, meant to characterize the position in which laryngeal features are licensed. The Laryngeal Constraint in effect says the following (this formulation has a straightforward implementation in FCT, it should be clear):

\section{Laryngeal Constraint (Lombardi 1991)}

\section{Laryngeal is licensed iff it occurs $[\mathrm{X} \ldots[+ \text { son }] \mathrm{Y}]_{\sigma}$}

Formulated in this way, the Laryngeal Constraint seems strange, a fact Lombardi also notes. Why this environment and no other? The way to make sense of these facts involving both place and laryngeal features, following especially Steriade (1993a-b, 1994, 1995a-b) and Kingston (1990), is to invoke the notion of segmental release. This expression refers (in phonetic terms) to the offset phase of a consonantal constriction, and to the highly perceptible burst that accompanies it (under the right conditions), known to provide important acoustic cues to contrasts in (especially) place and laryngeal features (Ohala 1990, and see Pickett et al. 1995 for a

${ }^{9}$ Positive formulations are clearly required in order to account for cases in which the complementary unlicensed environment does not constitute any sort of domain at all. Word- and foot-initial positions are often singled out as regions of licensing (see Steriade 1995a); the complementary environments are undefined. 
recent overview of the literature on the more general CV vs. VC transition distinction and related discussion). It is this high perceptibility of released feature contrasts that underwrites the presence of such features. In the grammatical account below, it will be by means of faithfulness constraints (thus phonetically grounded) that we capitalize on this idea.

It is release that rationalizes an otherwise mysterious constraint like (24). This constraint roughly sums up the position in which release is virtually phonetically inevitable: an onset consonant is released into a succeeding sonorant as the syllable opens up to the nucleus. Due to restrictions on sonority sequencing, a [+sonorant] segment following a nasal in the syllable onset will normally be either a liquid or a vocoid (glide or vowel), hence this wording in our original statement above. The restriction to tautosyllabicity is important, since nasals frequently assimilate to these segments across a syllable boundary, e.g., $/ . . . N+$ r.... $\rightarrow$ [...r.r...] (see Padgett $1995 \mathrm{c}$ for various cases); thus release is favored in part by onset status. However, release is not reducible to a constraint on the number of onset place features, contrary to the classical licensing view. While nasals frequently must be place-linked in onset [NC clusters, as in the Luganda example in (22)e, they fail to assimilate in onset [CN clusters like those of Russian shown in (23)b. It is release that illuminates this distinction: the nasal occupies a position of universal release in the latter, but not in the former. A similar point can be made concerning laryngeal neutralization: the devoicing seen in Russian examples like $/ \mathrm{v}+$ plavl $^{\mathrm{y} a t^{\mathrm{y}} /} \rightarrow$ [fplavl $\left.l^{\mathrm{y}} \mathrm{at}^{\mathrm{y}}\right]$ 'fuse in' motivated a licensing constraint like that of (24) in Lombardi (1991), rather than a prohibition on onset [voice] per se, since this feature is otherwise sanctioned in onset obstruents. More generally, Steriade (1993b, 1995b) argues that when prosody bears on licensing, it does so only indirectly; the real licensing action involves perceptually motivated factors including release. For languages lacking onset clusters like $n d$ and $f p l$, the distinction between classical prosody-based licensing and an account based on release disappears: there is only one onset consonant, and it is necessarily released. It is the more complex scenarios engendered by Russian and Luganda (among many others) that motivates release as the pivotal notion.

Steriade follows and expands on previous work appealing to release in phonology, notably McCawley (1967), Selkirk (1982) and Kingston (1990). As in Selkirk (1982), we understand release here as a featural property of segments; thus $n$ in Russian kniga is [+release]. ${ }^{10}$ As a first step toward determining the distribution of this feature-always dependent on both prosodic and segmental environments, as seen above - let us assume that all output segments preceding a tautosyllabic sonorant are necessarily [+release], a constraint on GEN in Optimality Theory. Now it is required of language particular phonology only to specify where else (if anywhere) segments are released. We can isolate two rough categories of broader release distribution that seem necessary to the theory (cf. Steriade 1994:208-9):

(25) Extra language specific environments of release

a. Word- (or utterance-) final consonants are [+release]

b. All consonants are [+release]

${ }^{10}$ Steriade (1993a, 1994) instantiates release as a positional entity in the representation akin to a Root node, a view abandoned in favor of direct appeal to the perceptual benefits of release in Steriade (1995b). 
(25)b characterizes the most release-permissive language, in which place and laryngeal distinctions are released-and therefore more likely to be preserved-in any consonant, including those that are word-final or before any other consonant. Bella Coola provides one example (Hoard 1978, Bagemihl 1992), and French another (Selkirk 1982 and references therein). (25)a represents a more conservative case, a language in which release is not possible before a consonant (except of course a tautosyllabic sonorant), but occurs at the end of a word. English possibly provides a case of this sort: nasal place is neutralized and assimilated within morphemes, as in camp (*canp) and rant (*ramt). But this contrast survives word-finally, as in cam and ran. The phonetic basis for this type is again reasonably clear: a release can be masked by the overlapping articulation of a following consonant; but there is no following consonant to mask the release of a word- (or utterance-) final segment. The general notion of release therefore potentially explains a distinction often associated with word-final 'exceptionality' (see especially Lombardi 1991 on this device). Yet exceptionality, unlike release, fails to make any connection between the word-final and pre-tautosyllabic sonorant environments (both often released), or to illuminate the hierarchy of neutralization captured by (25) and the statement in GEN; nor does it explain why it is precisely final consonants that can be special (they can be released when preconsonantal consonants cannot), and not initial consonants. (Byrd 1992 makes similar points.) This promise of drawing together the word-internal and word-final facts clearly makes the release idea worth pursuing. Whether (25)a-b themselves represent constraints available for ranking, or require further scrutiny and perhaps subdivision, is unclear. ${ }^{11}$ Since the focus here is on assimilation within words, by preconsonantal nasals that are unreleased, we can make the following simplifying assumption for the languages under discussion: consonants are [+release] before tautosyllabic sonorants (necessarily by GEN), otherwise unreleased.

The idea that features under release are perceptually more salient suggests a grammatical implementation via release-sensitive faithfulness, under the natural assumption that whether a feature is preserved (as well as other faithfulness issues) can depend on such perceptual differences. This strategy builds on Selkirk (1994), who argues for the subdivision of faithfulness constraints according to the prosodic position of the relevant segment-onset vs. elsewhere, etc. (see also Beckman 1995 and Lombardi 1995a). The major point of the discussion above is that the right distinction for place assimilation instead involves release, and so follows from prosody only indirectly. This leads to faithfulness distinctions like the following:

(26) Feature faithfulness, release-sensitive and general

a. MAX(PLACE): Every input place feature has an output correspondent.

b. $\operatorname{MAX}_{\text {REL }}$ (PLACE): Let $S$ be a [+release] output segment. Then every place feature in the input correspondent of $S$ has an output correspondent in $S$.

c. Universal ranking: $\operatorname{MAX}_{\mathrm{REL}}(\mathrm{PLACE}) \gg \mathrm{MAX}(\mathrm{PLACE})$

${ }^{11}$ Steriade (1995b) argues for more subtle phonetically-based discriminations based on cases of laryngeal neutralization, and see Selkirk (1982) for a detailed discussion of the facts of English phonetic release. It seems clear that [release], like all features, though tied to phonetic facts, must also abstract away from them to some degree. 
The formulations here assume an understanding of featural faithfulness due to McCarthy and Prince (1995) (which see for extensive argumentation). Recasting the proposals of Prince and Smolensky (1993) on faithfulness, McCarthy and Prince argue for an understanding of this notion in terms of correspondence, at either the segmental or featural level. ${ }^{12}$ For our purposes it will always be clear what the input-output segmental correspondences are, and so no further mention of this issue will be required. (26)a simply requires that any underlying place feature be maintained in the output. (26)b is more discriminating, requiring that a segment that is released in the output maintain its underlying place specifications. By hypothesis released distinctions are better preserved than others; hence the fixed ranking between the two constraints in (26)c. The MAX family of constraints only militates against feature loss; another family (called DEP, see McCarthy and Prince 1995) works against output material that is not in the input, featural 'epenthesis'. As we will see below, NPA can lead to the loss of input featural material, violating MAX(PLACE), as well as the establishment of association lines not in the input, violating DEP(LINK) (see Itô, Mester and Padgett to appear on the full array of featural faithfulness constraints); both types of violation occur for example in $/ \mathrm{n}+\mathrm{gb} / \rightarrow \mathrm{gmg} g$. There will be no need to distinguish these violations, however, and in order to simplify the tableaux all faithfulness constraints will be lumped together into FAITH and FAITH REL $_{\text {constraints. }}$

In order to see the release-sensitive faithfulness idea at work, we now need to motivate an account of assimilation or multiple linking itself. This is the job of the following section. The idea is simple, though: once multiple linking between two segments $C_{1} C_{2}$ (with competing place specifications) is required, then the direction of assimilation will be determined by releasesensitive faithfulness. If $C_{2}$ is released and $C_{1}$ is not, then the former's place feature will necessarily win out over the latter's.

\subsection{The Spreading Imperative}

If release-sensitive faithfulness provides the real content of the notion license in the case of place assimilation, the next question might be what is left of the feature geometric understanding of NPA as a place spreading phenomenon. In fact, some direct imperative of featural spreading is required by our theory. To see why, consider first total NPA to complex segments, as seen in Kpelle gmgb earlier. Reverting to the classical licensing account momentarily for the sake of discussion, consider the tableau below. The problem with this indirect view of spreading is that it predicts only partial NPA to such complex segments, never total NPA (recall that we assume a world devoid of the organizing class nodes of FG). LICENSE and HAVEPLACE together merely require that the nasal receive some place feature from the following segment. Any further spreading to derive $I m g b$ can only be in violation of markedness-a complex nasal is more

\footnotetext{
12 Though McCarthy and Prince themselves clearly note the possibility of featural correspondence, featural faithfulness is generally handled in that work by means of separate Identity constraints, and (in a related move) features are generally viewed as attributes of segments rather than entities entering into correspondence relations themselves. One possible implication of the feature-as-attribute view is a loss of the chestnut autosegmental distinction between two segments sharing a feature value $F$ and two segments each separately specified for $F$ (with concomitant implications involving geminate integrity or inalterability effects). Nothing in the analyses here seems to depend on the more conservative decision to employ featural correspondence (and so clearly preserve such distinctions).
} 
marked than a simple one-and faithfulness (if the input itself is not $7 m g b$ ). Candidate (27)c has doubly linked [dorsal], but not [labial].

(27) Licensing predicts only partial NPA

\begin{tabular}{|l||c|c|}
\hline Input $=/ \mathrm{N}+\mathrm{gb} /$ & HAVEPLACE & LICENSE \\
\hline \hline a. $\quad \mathrm{Ngb}$ & $* !$ & \\
\hline b. $\quad \mathrm{ngb}$ & & $* !$ \\
\hline c. $\mathrm{ngb}$ & & \\
\hline
\end{tabular}

This problem carries over to other indirect accounts of spreading. Spreading cannot follow from segmental or featural markedness alone (as in McCarthy 1994, Beckman 1995), for reasons just given: the segment produced by total assimilation is more marked. Nor can a constraint in the spirit of * F F (barring two instances of the same feature, identical or not, Archangeli and Pulleyblank 1993, Kiparsky 1993), if place features are privative as widely assumed $-\eta 7$ has no value for [labial] beside that of $g b$. Similar arguments for a spreading imperative come from facts of [voice] assimilation, as in Russian /ot+davaty/ od.da.vaty 'give up' (see Hayes 1984 and Kiparsky 1985). The voiced segment produced by spreading is more marked than what failed assimilation would produce, and this feature is again widely (though not universally) viewed as privative (Mester and Itô 1989, Cho 1990, Lombardi 1991).

By 'spreading imperative' we mean a constraint requiring of a feature that it be multiply linked (or spread), or extended in its domain in the output. Something close to this is widely employed in the OT literature already in the form of featural alignment constraints (Kirchner 1993, Smolensky 1993, Pulleyblank 1994, Cole and Kisseberth 1994 and many others). Alignment could be made to serve our purposes, but an interesting point arises here: alignment as typically construed incorporates directionality into constraint statements (see Prince and Smolensky 1993, McCarthy and Prince 1993a), while it is arguably true (in the featural domain at least) that directionality of spreading follows from other factors. The source of vowel harmony-accounting for its apparent directionality -is typically a vowel in a more prominent position, for example stressed, word-initial, etc., as Steriade (1995a) notes. Directly related to this are the findings above concerning release and NPA: in place assimilations, it is the released segment whose place wins. (The reader might look once more at the patterns laid out in (22) to see this.) Given this fact, it would be odd to stipulate the typically leftward spreading of place in NPA (a point similarly made by classical licensing accounts), and it would in fact be incorrect for German habm etc. (where the obstruent is released into the nasal, itself unreleased). The constraint employed here therefore abstracts away from directionality; the most general formulation might be the following: every feature is linked to every segment (in some domain, e.g., Pwd). More formally, with $x$ ranging over features and $y$ over segments,

(28) SPREAD(X): $\quad \forall_{x y}, x(y) \quad$ (in some domain) 
As with alignment (see references above), this formulation is very general. Real outcomes will be reined in by other constraints on locality (no segment skipping), markedness (don't derive bad things), and so on. In what follows we will ignore these issues; the essential point is simply that some spreading imperative is required in order to explain facts of assimilation. ${ }^{13}$ Various researchers have suggested plausible phonetic bases for such a constraint; it will enhance the perceptibility of the affected feature by extending it (Steriade 1993b, Kaun 1994, Cole and Kisseberth 1994), eliminate contrasts in non-prominent locations (Steriade 1993b, 1995a,b, and the discussion of release above), and lead to fewer overall articulations/specifications (Mohanan 1993, Cole and Kisseberth 1994). It may be that SPREAD must ultimately be reduced to more fundamental constraints invoking such functional notions; such a move is well beyond the scope of this work, however.

The core of the NPA account is now at hand. The impetus is provided by SPREAD(PLACE) $(\forall x y \in$ Place, $y$ a segment, $x(y))$ while release-sensitive faithfulness ensures that released segments are the source of assimilation (and unreleased segments the targets). As Lombardi (1995a) shows in a parallel examination of [voice] assimilation facts, there are only two rankings of the relevant constraints to consider. (Recall that the ranking FAITH $_{\text {REL }} \gg$ FAITH is fixed.) First, assimilation will occur as described above whenever SPREAD(PLACE) outranks FAITH, as shown below for our example $\eta m g b$ again. The input for this form has been changed arbitrarily to $/ \mathrm{n}+\mathrm{gb} /$, where the nasal segment bears its own [coronal] specification, a point to which we return momentarily.

(29) Place assimilation by SPREAD(PLACE) $>>$ FATTH

\begin{tabular}{|c|c|c|c|}
\hline Input $=/ \mathrm{n}+\mathrm{gb} /$ & FAITH $_{\text {REL }}$ & SPREAD(PLACE) & FAITH \\
\hline a. $\quad \mathrm{Ngb}$ & & $*$ !* & \\
\hline b. ngb & & $* ! * *$ & \\
\hline c. ggb & & $* !$ & $3 *$ \\
\hline d. nd & $* ! * *$ & & 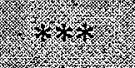 \\
\hline e. ngmgb & & & 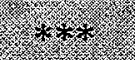 \\
\hline
\end{tabular}

SPREAD(PLACE) is understood crucially to quantify universally over place features in a gradiently violable way, and supersedes the provisional constraint NPA of section 2.1. Candidate (29)a violates this constraint twice: in this two-segment span, there are four possible place featuresegment links ([labial and [dorsal] each with each segment); but two do not obtain. (In what

${ }^{13}$ Spreading of consonantal place features will be confined to a cluster of strictly adjacent consonants, for instance, given two assumptions: spreading cannot 'skip' a vowel segment (see Archangeli and Pulleyblank 1994, Itô, Mester and Padgett to appear on locality), and spreading cannot target a vowel segment either. The latter follows from the unity of place and oral stricture (Padgett 1991, 1994, 1995c, cf. the gesture of Browman and Goldstein 1989): spreading a stop articulation to a vowel would illicitly 'harden' the vowel (see Ní Chiosáin and Padgett 1993). 
follows we will continue to count violations only within the consonant cluster, ignoring extra violations shared by all candidates for failure to Spread throughout an entire word; see footnote 13.) Candidate (29)b violates the same constraint three times, since there are three possible but non-occurring place-segment links. In contrast, candidate (29)c violates SPREAD only once ( $g b$ 's [dorsal] feature has spread), but still fatally. Candidate (29)d is an interesting attempt to circumvent SPREAD violations, without totally assimilating to $g b$, by losing the input place specifications of this segment; further, it preserves (and spreads) the input [coronal] specification of the nasal. Nevertheless, this move violates FAITH $_{\mathrm{RE}}$, since the input place features of $g b$ have no output correspondents, and $g b$ is the released segment in the real examples we have in mind, e.g., Kpelle $\not m g b i \eta$ 'myself'. (29)e wins by passing both of these top-ranked constraints. As Lombardi (1995a) notes, these constraints therefore need not be ranked. In fact, given the elsewhere relation between the two faithfulness constraints, a released segment can never lose as in (29)d (all else equal). In the tableaux that follow, we will therefore omit such candidates and the constraint FAITH REL .

For completeness, the FAITH violations are counted in the following way: candidate (29)a incurs one MAX(PLACE) violation, since the nasal's input [coronal] specification is lost; candidate (29)c in addition violates DEP(LINK) once, given the establishment of a link between the nasal and [dorsal] in the output; in (29)d released $g b$ has lost both its [labial] and [dorsal] specifications; further, it has acquired a link to the nasal's [coronal] feature, hence three FAITH $_{\text {Res }}$ violations, mirrored in the more general FAITH constraint as well; finally, in (29)e the nasal's input [coronal] specification is again lost, and both [labial] and [dorsal] are linked unfaithfully to that nasal.

Failure of assimilation results from the reverse ranking FATTH $\gg$ SPREAD(PLACE), as the reader can verify by studying the above tableau. Hence the minimal typology of assimilating versus non-assimilating languages is derived. A point left so far untouched involves a well-known asymmetry between nasals and obstruents: the former are more likely to assimilate than the latter, a fact leading to contrasts within languages like English aptitude versus *amtitude. The account invoking release discussed above, which of course extends to cover cases where obstruents are targets of assimilation, must be supplemented with a recognition of this difference between obstruent and nasal place. The most direct attack on this problem involves another breakdown of place faithfulness with a fixed ranking: FAITH(OBS-PLACE) > FAITH(NAS-PLACE). The intervention of SPREAD(PLACE) between these constraints will give the English-like output contrast we seek. This distinction between nasal and obstruent place faithfulness once again finds roots in facts of perception: nasal place is more difficult to perceive than obstruent place, since the former lacks significant burst cues. (See for example Ohala and Ohala 1993:241-2 and references therein on this distinction, and its relevance to the place assimilation asymmetry.) Since obstruent assimilation will not be a concern of ours, we can safely by-pass this distinction in what follows.

As a matter of interest, the account of place assimilation proposed here does not rely' in any way on assumptions about the degree of input specification of the target segment. The [coronal] input specification attributed to the nasal in (29) was posited simply to help make this point. As the reader can verify, the outcome of tableau (29) is again the same if the nasal is assumed to be unspecified $N$, or specified for another place. This account follows Prince and Smolensky (1993), Itô, Mester and Padgett (to appear) and others in limiting constraints other than those of 
faithfulness to statements about the wellformedness of the output. Under this view of things, no imperatives concerning input degree of specification are possible; the point of the references cited and the example here is that they are also unnecessary, given the right theory of output constraints. This thinking also follows Itô and Mester (1989), Mohanan (1991), Smolensky (1993) and Steriade (1995a) in rejecting so called 'naive' uses of underspecification in order to account for assimilatory facts (achieving NPA by stipulating an input-unspecified nasal, for example). In its least embellished form, such a use of underspecification only begs many of the essential questions about place assimilation posed at the outset.

To conclude this section, the preliminary answers we now have to the questions about NPA raised at the outset of section 3 are as follows. Assimilations occur due to the workings of a family of SPREAD constraints plausibly grounded in facts of perception and articulation; place assimilation falls into this family. Directionality of place assimilation is an artifact of releasesensitive faithfulness; more generally, directionality effects will often be tied to such prominential asymmetries. Nasals are more common victims of place assimilation than obstruents given another dimension of prominence involving nasal versus obstruent place, with nasal place being the less salient (and therefore faithful). These ideas are broadly similar to many raised by Mohanan (1993) and Jun (1995) in addressing place assimilations; these works in addition address other questions concerning place assimilations not raised here. More generally, the success of this account is tied to its appeal to constraints with bases in facts of phonetics, placing this approach in a growing tradition (see most notably Archangeli and Pulleyblank 1994 and Steriade 1993b, 1995b).

\section{Partial Assimilations}

This final section has two main goals. First, it gives empirical substance to the arguments from section 2 in favor of FCT, by surveying a range of cases of partial NPA, involving various complex segment types. This endeavor documents robust partial class behavior for the class Place, and therefore broadens the results of Padgett (1995a), where the same is done for Color. Second, it integrates ideas of the previous section about NPA into the analysis of partial assimilation, and shows that the arguments for FCT still hold.

\subsection{Survey}

In order to demonstrate the existence of partial nasal place assimilation to a complex segment, one needs to satisfy on several points. First, is assimilation really partial, and phonologically so? The distinction between $\eta m g b$ and $\eta g b$, say, is phonetically subtle, and transcription of the latter might be written off to error; or if it is accurate, the whole distinction might be attributed to phonetics, perhaps an artifact of different degrees of gestural overlap in speech (Browman and Goldstein 1989). Second, are the NC sequences under consideration really bisegmental as an analysis in terms of place assimilation implies, or are they prenasalized single segments? Third, since the frequent result of partial NPA is $\eta$, a segment associated with nasal 'placelessness' by the work of Trigo (1988), could $n g b$ actually involve a completely unassimilated nasal, phonologically $N g b$ (and hence showing no partial assimilation at all)? Finally, is the trigger segment truly phonologically complex? If $g b$, say, were just the surface embellishment of an underlying /g/, then perhaps $\mathrm{g} g b$ is totally assimilated after all. 
Some of these issues will be addressed as we survey particular cases below, but a few general remarks now will limit the field of questions somewhat. First, the question about prenasalization carries little weight, because of a range of compelling arguments against a phonological distinction between mono- and bi-segmental NC ${ }^{14}$ (Herbert 1975, 1986, Feinstein 1979, Clements 1986, Duanmu 1990, Padgett 1991, 1995c, Piggott 1992, Steriade 1993a). On principled grounds we therefore make no distinction in segmental status between the nd sequence in Lu.ga.nda and the same sequence in English Me.lin.da - both are bisegmental place assimilated $\mathrm{NC}$, and they differ only in syllabification as shown. In fact several of the languages surveyed below involve NC sequences that are bisegmental without controversy, with a nasal that is clearly syllabified differently from the following $\mathrm{C}$ (i.e., either syllabic itself or a coda).

Turning to the interpretation of $\eta g b$ as $N g b$, pursuing Trigo (1988): the idea here might be that assimilation fails entirely, due to a prohibition (that is assumed here anyway) on complex $\mathrm{gm}$. This idea rests on an understanding of $\eta$ as a sort of phonetic realization of the phonological, debuccalized $N$. Yet if we truly have output $\eta g b$ - with a velar nasal whose velarity is gesturally merged with that of $g b$ (pending direct investigation, the best we can do here is rely on phonetic descriptions where they seem most clear) - it is necessary in an output-oriented theory to produce it. (See the relevant discussion in McCarthy and Prince 1995 against a relegation of systematic output segmental content to 'phonetic interpretation', as done by the FiLL constraint of Prince and Smolensky 1993.) Could it be that the grammar indeed generates a dorsal nasal, yet one that is nevertheless unassimilated? This interpretation can be rejected as a general move on empirical grounds, putting aside its implausibility from the standpoint of the OCP (given the adjacent [dorsal] specifications). As a default nasal place, $\eta$ is a competitor with [coronal] $n$; both are found with great abundance in languages as place-neutralized nasals. Yet no report of $n g b$ (where assimilation otherwise obtains, i.e. to simple segments) exists to the best of my knowledge, something that would be expected if the nasal can resort to its own unassimilated place. If the nasal is indeed [dorsal], and if it shares this place with $g b$, then we have partial place assimilation. For reasons to be discussed, partial assimilation to labiovelars indeed typically gives velar $\eta$ rather than labial $m$; but in infrequent instances (involving a trigger $w$ ) $m$ results instead. The existence of this alternate pattern is only possible if the nasal is partially assimilating, since [labial] is a default place in no theory. Finally, it should be possible in principle to show for some languages with $\eta$ before labiovelars that the default nasal is actually $n$. Spanish is a possible instance: in most dialects, the default nasal is coronal; but partial assimilation to $w$ produces $\eta$, as in $u g w e \beta o$ 'an egg' (Harris 1969, 1984).

The other concerns mentioned above will be addressed where appropriate below. To preview what follows, four different types of complex segment are considered one at a time. These are clicks (labio- and coronovelar), palatals (coronovelar), glides (labiovelar $w$ and coronovelar $j$ ) and labiovelar stops like $g b$. For each type, evidence of partial assimilation is found. The survey is necessarily brief for reasons of space. Most attention, and actual analysis are restricted to the final category of labiovelars, with an analysis of Gã, a Kwa language.

\footnotetext{
${ }^{14}$ More accurately, monosegmental NC exists only as a phonetic realization of voicing or perhaps sonorancy in languages having no nasal vs. voiced obstruent distinction, a subgroup we are not concerned with (see Piggott 1992).
} 


\subsubsection{Clicks}

Clicks are phonetically complex, in that they require a velar constriction and some other constriction further forward, coronal or labial. Building on Chomsky and Halle (1968) and Halle (1983), Sagey (1986) argued for the complex status of clicks on phonological grounds as well, attempting to show the relevance of each articulator to some phonological process. ${ }^{15} \mathrm{As}$ Maddieson and Ladefoged (1989) point out, such an argument for the presence of [dorsal] in clicks comes from NPA in Bantu languages having clicks. The relevant examples involve the prefixation of a nasal-final class marker, as in the Zulu examples in (30). The final nasal of the class 10 prefix iziN-assimilates across all places of articulation, as shown in (30)a. Before the clicks in (30)b (respectively dental, palato-alveolar and lateral), assimilation produces simple velar $\eta$, as before $k$. (Doke 1926:78, 1931:14,52-3, data from the latter. The clicks are also voiced following the nasal.)

\section{Zulu NPA}

\begin{tabular}{|c|c|c|c|}
\hline $\begin{array}{l}\text { izim-paphe } \\
\text { izin-ti } \\
\text { izin-kezo }\end{array}$ & $\begin{array}{l}\text { 'feathers' } \\
\text { 'sticks' } \\
\text { 'spoons' }\end{array}$ & b. & 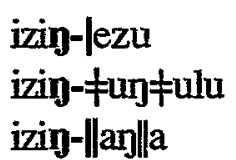 \\
\hline
\end{tabular}

The description by Doke is clear on this partial assimilation. Further, Maddieson and Ladefoged (1989) imply that it is true of other Bantu languages with clicks. If NPA is phonological, then these data demonstrate a [dorsal] place in clicks. Since clicks are distinguished by their forward articulations, they must in fact be complex, and assimilation to them is therefore partial.

NPA in Zulu is not plausibly viewed as a purely phonetic phenomenon on the order of gestural overlap. Assimilation brings about a range of systematic and neutralizing changes in the quality of the following consonant that could not follow simply from overlap, including deaspiration, voicing, nasalization and hardening (see Doke references). Further, Maddieson and Ladefoged point out that the purely velar outcome is not an articulatory necessity. Zulu contrasts nasalized clicks to the sequences illustrated above; nasalized clicks have nasality during both articulations of the click. None of this is to say that the properties of NPA in Zulu seen here lack a basis in phonetic effects; surely the opposite is true. Nevertheless, NPA is phonologized.

A germane question at this point concerns the nature of partial NPA to clicks: why is it [dorsal] that assimilates, and not the other articulator feature? As we will see, this skew in results occurs with partial NPA before labiovelars also. According to Ohala and Lorentz (1977) and Ohala and Ohala (1993), the phonetic motivation for this imbalance is most likely acoustic: the spectral properties of a nasal with velar closure are necessarily those of simple $\eta$-it makes no difference what any articulators further forward may be doing. Therefore, before a complex segment with largely overlapping places, one of which is [dorsal], pure $\eta$ may often win out

${ }^{15}$ Halle (1995) argues that clicks have only one 'designated articulator', [coronal] in the case of dentals and palatals, [dorsal] for alveolars and laterals. He specifies all clicks [+high] though, and gives all non-labial clicks an [anterior] value, thus making all clicks complex in essence. The data below show that [dorsal] is an element of all clicks. 
perceptually. ${ }^{16}$ It is more difficult to determine how this insight should bear on our grammatical formulations. This section together with those following show that assimilation can be phonologically total or partial before complex segments. (It is useful to bear in mind that total assimilation as well as partial assimilation is a common pattern in labiovelar stops; this is a grammatical choice.) This fact may have phonetic underpinnings like the one just mentioned (only tendential, note, and not determinant), but how do we express its phonological realization? The assumption here is that the constraint *COMPSEG makes the determination between full and partial assimilation, as seen earlier. Once partial assimilation is favored, the selection of [dorsal] $\eta$ can be viewed as conforming to perceptual demands. Whether the latter assumption should be phonologically implemented as well (or remains a purely phonetic effect) is unclear; it is violated at least in languages where the nasal becomes $m$ before $w$ (see section 4.2.4, and also the Catalan case just below). This question need not be resolved here, since for our purposes the important fact is simply that partial assimilation occurs under phonological control.

\subsubsection{Palatals}

The featural make-up of palatal and alveopalatal segments is not a matter of consistent agreement, but a widely-held view due to Keating (1988) treats them as complex segments, both [coronal] and [dorsal]. In this light, consider a case of partial assimilation to palatals from Catalan. Catalan has the following coronal segments, specified roughly (and fully) as follows: ${ }^{17}$

Coronals of Catalan (Mascaró 1976, Recasens 1991, 1993)

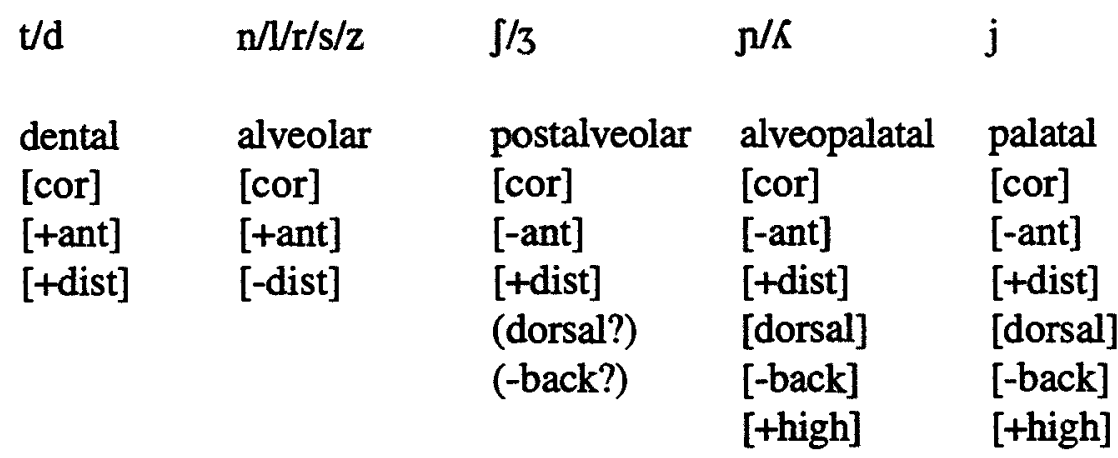

These feature specifications follow Mascaró (1976), who specifies postalveolars as [+cor, -ant, +dist, -back] and specifies the (alveo)palatals as additionally [+high]. They also seem consistent with the careful descriptions of Recasens (1991, 1993) (modulo footnote 17). According to these references, NPA by $n$, when occurring before $\delta$ and $j$ in Central Catalan, results not in $n$, an identically specified (for place) phoneme of the language, but in a postalveolar nasal transcribed

${ }^{16}$ In both clicks and labiovelars the velar articulation precedes the other one in time. At least in labiovelars this lead is very slight, however, and is a less likely source of explanation for simple $g$ under assimilation, according to Ohala and Ohala.

${ }^{17}$ Recasens describes $t / d$ as apico-dentals in contrast to Mascaró's [+dist] specification. He also indicates variation between [+dist] and [-dist] for $s / z$. 
[n,]. This is the place of articulation of $\int / 3$, and $n$ appears as [n,] before these segments as well. Representative examples of NPA before these coronals are given below.

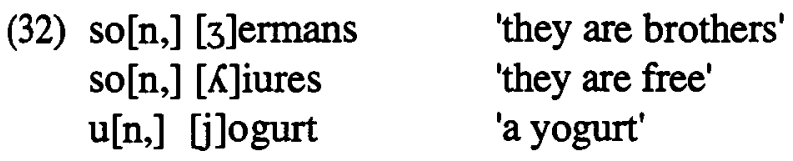

According to Recasens, this partial assimilation is obligatory. In contrast, assimilation before $\rho$ is total, giving geminate $n n$ (perhaps because $n, n$ is a sequence of too similar things in some sense, cf. Steriade's 1982 Shared Features Convention). Recasens suggests that assimilation can be total before all of the (alveo)palatals in some other Catalan dialects. In order to capture the partial assimilation seen above, Mascaró simply omitted [high] from a rule of NPA employing greek variable notation. This simple tack becomes impossible in FG, if the relevant process is Place node spreading. In FCT we might hypothesize that NPA succeeds in causing linkage of only the coronal-related features [coronal, -ant, +dist] before (alveo)palatals, due again to the workings of *COMPSEG. Whether this is correct or not, (alveo)palatals are more complex than coronals like $t$ under any theory, and assimilation here is in some way partial.

It is more difficult to say whether this process should be viewed as part of a phonological NPA. Mascaró (1976) (and many subsequent works) included these partial assimilations under a general phonological rule of NPA in Catalan. This rule is obligatory within words, but in Central Catalan is optional across words-except when $n$ appears before another coronal, as in (32) and examples like so[n] [d]os 'they are two'. (See especially Recasens 1993, p.190.) These facts might mean that general cross-word NPA is a phonetic process, and/or that assimilation before coronals is a process separate from general NPA. There is much interdialectal variation in the degree of obligatoriness of NPA across words in Catalan, however, and the facts need further study. As a separate matter, it is interesting that partial assimilation produces a basically [coronal] segment, rather than a [dorsal] one, in apparent contradiction to Ohala's generalization noted earlier. Perhaps this is because the [dorsal] component of (alveo)palatals is vocalic, and so cannot render nasality effectively velar as it can with other complex segment types. Further, assimilation to the stop [coronal] articulation is favored for reasons of structure preservation (see next section).

\subsubsection{Glides}

The glide $w$ is phonetically labiovelar, and $j$ is coronovelar if this is the right understanding of palatals (Keating 1988), as noted above. Yet the glides raise questions of their own, and so merit separate mention.

Assimilation by nasals to $w$ in languages is typically partial. The following are just representative illustrations of the many existing alternations. Many others are cited in Ohala and Lorentz (1977), Ohala and Ohala (1993), and Cahill (1995), and they are easy to find by perusing grammars. 
(33) NPA to $w$

$\begin{array}{cll}\text { [labial] only - Ndali: } & \mathrm{N}+w \rightarrow m b & \text { Herbert (1986) } \\ \text { Chukchee } & \mathrm{N}+w \rightarrow m w & \text { Skorik (1961) } \\ & & \\ \text { [dorsal] only - Kihungan: } & \mathrm{N}+w \rightarrow \eta g w & \text { Clements (1987) } \\ \text { Bakweri } & \mathrm{N}+w \rightarrow g w & \text { Kingston (p.c.) }\end{array}$

Though assimilation of the [dorsal] articulation appears by far more common, examples involving [labial] exist, as shown above. $w$ is therefore different from clicks and perhaps labiovelar stops (see below) in that there is a choice of which articulator to spread. We leave open here the question of why $w$ allows this choice, and why the preference nevertheless remains for [dorsal] spreading.

It seems clear that at least many cases of NPA giving results as in (33) before $w$ are truly phonological. Consider one example from Luganda (Ashton et al. 1954, Chesswas 1963; segments of interest bolded):

NPA in Luganda

$\begin{array}{llll}\text { a. } \begin{array}{l}\text { mpandiika } \\ \text { ampulira }\end{array} & \begin{array}{l}\text { 'I write' } \\ \text { 'He hears me' }\end{array} & \begin{array}{l}\text { cf. oku-wandiika } \\ \text { cf. oku-wulira }\end{array} \\ \text { b. } \quad \begin{array}{l}\text { mbala } \\ \text { mmomba } \\ \text { ndya } \\ \text { nnonda }\end{array} & \begin{array}{l}\text { 'I count' } \\ \text { 'I escape' }\end{array} & \begin{array}{l}\text { cf. oku-bomba } \\ \text { cf. oku-lya } \\ \text { cf. oku-londa }\end{array} \\ \text { c. } \quad \begin{array}{l}\text { nziba } \\ \text { nzita }\end{array} & \text { 'I choose' } & \text { cf. oku-bba } \\ \text { nzisa } & \text { 'I steal' } & \text { 'I kill' } & \begin{array}{l}\text { cf. oku-tta } \\ \text { cf. oku-ssa }\end{array}\end{array}$

This NPA (of which only a selection of forms is given) evinces properties not likely to follow directly from phonetic accounts involving overlap of articulations or acoustic/perceptual properties. The hardening of $w$ to $p$ itself seen in (34)a is arguably one. More telling even are those seen in (34)b-c. In the former we see NPA giving either NC or NN as a result, depending on whether a nasal consonant appears in the second syllable of the stem. The latter illustrates a seeming substitution of the sequence $n z i C$ for all stems beginning in geminate $\mathrm{CC}$-in order to indicate first person singular marking, otherwise marked by a straightforward archiphonemic segment $N$ (see references cited for details). The point is that this NPA, like many others including partial assimilation to glides, is grammatical in nature.

In what sense is assimilation to $w$ partial? Though this segment is phonetically complex, it can be viewed as a simple [labial] or [dorsal] segment under theories of underspecification, since these properties of $w$ are mutually dependent (see for example Steriade 1987 on $u$ ). This mutual 
dependence of the place features is a problem for underspecification in itself, as Steriade (1995a) notes, since it means that choice of [labial] vs. [dorsal] as underlying is entirely arbitrary in the theory. Another problem for the underspecificationist view of $w$ involves cases where this segment behaves as both [labial] and [dorsal] within a language, depending on the process considered (see Ohala and Ohala 1993:237 for examples). Within OT, a theory of output constraints, forms like ngw are unavoidably partially assimilated, since $w$ is (usually) both [labial] and [dorsal] in the output. Though the result of partial assimilation to $w$ can clearly be eluded by invocation of intermediate representations (partially specified) or other devices, nothing seems gained by the attempt, and it is preferable to confront the facts as they present themselves.

Luganda $m p$ and Ndali $m b$ of course avoid surface partial assimilation, by simplifying the hardened trigger segment to [labial]. (Here SPREAD is fully satisfied, at the expense of an FAITH REL violation.) Results like $\eta g w, \eta w$ and $m w$, on the other hand, show partial assimilation in the output. Hardening or 'obstruentization' of $w$, as in $m b$ and $\eta g w$, follows a pattern seen generally for continuant triggers of NPA, and is due to an interaction of factors explored in Padgett (1994, 1995c). Briefly, articulator features and oral stricture features like [continuant] and [consonantal] are viewed as 'bundled' together in a unit called an articulator group, analogous to the 'gesture' of Browman and Goldstein (1986 et seq.). Place assimilation therefore means assimilation of place and oral stricture properties. Second, nasality combined with [-cons] and/or [+cont] is highly marked in languages. NPA to a fricative or glide threatens to create such feature cooccurrences; hardening of the assimilated 'gesture' is just one of many ways to avoid this undesirable outcome. Let Art $_{\mathrm{s}}$ mean a [+cons, -cont] articulation, and $\mathrm{Art}_{\mathrm{V}}$ a [-cons] articulation; partial assimilation and hardening in the case of $\eta g w$ are illustrated below.

$$
N+w \rightarrow \eta g w
$$

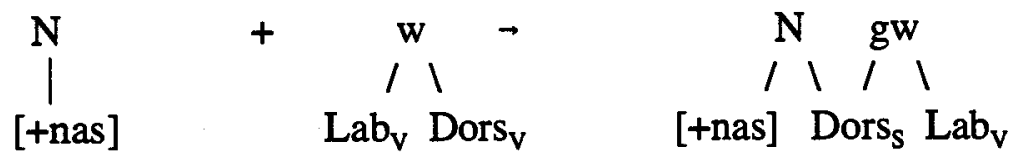

The representation derived is arguably the correct one for $\mathrm{gw}$ as well; hardening in this case is covert (for arguments see Steriade 1993a and Padgett references).

Partial assimilation to the glide $j$ occurs also. This seems clearest in cases like Kihungan $N+$ $j \rightarrow \eta g j$ (Clements 1987), where the nasal is purely [dorsal]. (Contrast such cases with that of Catalan discussed above, where [coronal] assimilates.) For reasons of space we leave the discussion of glides here. See Padgett (1995c) for more discussion.

\subsection{Labiovelars - Gã}

Labiovelars like $k p$ and $g b$ make up a well-known class of complex segments. Though certain instances have sometimes been treated as simple [labial] or [dorsal] according to gaps in a language's inventory (see especially Anderson 1976), most are clearly phonologically complex. In Gã for example, a Kwa language spoken in Ghana, the series of phonemes $k p, g b, g m$ contrast with both $p, b, m$ (respectively) and $k, g, \mathfrak{l}$. NPA before labiovelars produces a labiovelar nasal in 
many languages, as in the Kpelle example Imgbin'myself' seen in section 2.2 (see especially Sagey 1986 on such assimilations). However, partial assimilation of the form $\eta g b$ and $\eta k p$ has been reported for various cases, including Gonja (Painter 1970:74), Nkonya, Efik (Ohala and Lorentz 1977, citing Reineke 1972 and Cook 1969 respectively), Birifor, Konkomba, Anufo, Konni, and others cited by Cahill (1995) (see references there). Working from his own field notes, Cahill notes the occurrence of both types of assimilation in Konni: NPA is partial within words (including compounds) and total across words. Here we examine something close to the reverse in Gã-assimilation is total within a morpheme but partial across a morpheme boundary.

Ga has NPA across all places, as shown below (Berry 1951, Kropp 1966, Kotey 1974, Ryder 1987). Word-initial nasals are syllabic. Assimilation to the labiovelars produces the complex nasal in the forms cited here, as in Kpelle. (Hyphen indicates a morpheme boundary.)

$$
\text { General NPA in Gã }
$$

$\begin{array}{llll}\text { jemba } & \text { 'character' } & \text { bepke } & \text { 'near' } \\ \text { m-bibii } & \text { 'my children's children' } & \text { D-klempe } & \text { 'my basin' } \\ \text { bonso } & \text { 'whale' } & \text { pmkpai } & \text { 'libation' } \\ \text { n-taoo } & \text { 'I want' } & \text { jmkpokua } & \text { 'nipple' }\end{array}$

However, in other cases assimilation to labiovelars is only partial. The relevant difference lies in the morphological make-up of the word: within morphemes assimilation is total, as seen above; across a morpheme boundary assimilation is partial. ${ }^{18}$ In the first two examples below, the assimilating nasal is a reduced form of the first person prefix $/ \mathrm{mi}-/$ (according to the references on Gã this reduction is characteristic of normal speech). In this case assimilation produces a pure velar, as shown.

Partial NPA across morpheme boundary

$\begin{array}{ll}\text { D-gbeke } & \text { 'my child' } \\ \text { D-kpai } & \text { 'my cheeks' } \\ \text { taan-kpee } & \text { 'sisal' }\end{array}$

A distinction like this based on morphological boundaries or domains invites various possible analyses. Earlier versions of this work ${ }^{19}$ accounted for partial assimilation across the morpheme boundary by relying on a constraint of feature-stem alignment (or 'crispness', see Itô and Mester 1994) that militated against cross-morpheme linkage. As it happens, the reliance on alignment in this case leads to complications in the account of NPA. A simpler analysis is possible by capitalizing on the assumption that constraints can be relativized directly to morphological domain or category. In particular, suppose that segmental markedness is computed differently in

\footnotetext{
${ }^{18}$ This statement may oversimplify, if the nasal in forms like Imkpai 'libation' is a synchronic marker of noun class; in any event, assimilation differs according to morphological domains.

${ }^{19}$ Arizona Phonology Conference handout.
} 
affixes (at least those considered here) than in stems. Adapting McCarthy and Prince's (1995) suggestion that affixes are phonologically less marked as a class, let the markedness constraint ${ }^{*}$ COMPSEG be articulated into two subconstraints, one for the affixes, ${ }^{*} \mathrm{COMPSEG}_{\mathrm{A}}$, and the more general *COMPSEG. If affixes are less marked, then the expected ranking between these constraints is $* \mathrm{COMPSEG}_{\mathrm{A}} \gg *$ COMPSEG (complex segments are less tolerable in affixes). Buckley (1995) (citing Cassimjee 1994) argues for tagging constraints with (ultimately) morphological domains in a similar fashion. There are in principle yet other ways of capturing morphological relevance, including incorporation of Lexical Phonology's notion level (Kiparsky 1985, Mohanan 1986, Pulleyblank 1986) into Optimality Theory (see especially McCarthy and Prince 1993b, and cf. Orgun 1994), and the definition of subgrammars based on (re)rankings of constraints (Itô and Mester 1995). The precise analytical choice made here is to a large extent independent of the basic point being made about partial class behavior.

Recall that a constraint SPREAD(PLACE) compels multiple linking; what leads to partial assimilation is the markedness of a derived complex segment, *COMPSEG. In the stem domain NPA is total (see the examples with complex segments in (36)). In order for this to be possible, we require the ranking SPREAD $\gg *^{*}$ COMPSEG. In affixes on the other hand, NPA is only partial before complex segments (see (37)); hence we have *COMPSEG $\gg$ $\gg$ SPREAD. The basic stemaffix dichotomy therefore lies in the central ranking ${ }^{*} \mathrm{COMPSEG}_{\mathrm{A}} \gg$ SPREAD $\gg$ *COMPSEG.

The role of faithfulness in the analysis must also be considered. In order for spreading to occur at all, we require SPREAD > FAITH, as noted in earlier sections. Now, since underlying complex segments (including $\mathrm{gm}$ ) must be allowed to surface when they occur before a vowel, as in ymele 'bell', faithfulness in some form must dominate the two *COMPSEG constraints. The constraint FAITH $_{\text {REL }}$ does this job: these segments are in a position of release. Therefore there is no crucial ranking between ${ }^{*}$ COMPSEG and the general FAITH constraint. For our purposes FAITH REL is an undominated constraint; to simplify things, we omit it from the following tableaux, and candidates violating it will not be considered. The full ranking to be considered is therefore implemented below. The nasal is arbitrarily given its own [labial] specification underlyingly simply to illustrate the necessary subordination of faithfulness to SPREAD (see section 3). 
(38) Total NPA within morpheme: ymkpai 'libation'

\begin{tabular}{|c|c|c|c|c|}
\hline Input $=/ \mathrm{mkpai} /$ & ${ }^{*} \mathrm{COMPSEG}_{\mathrm{A}}$ & SPREAD & ${ }^{*}$ COMPSEG & FAITH \\
\hline 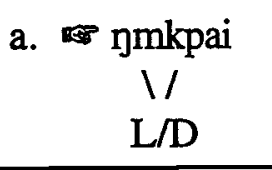 & & & & \\
\hline b. $\quad \begin{array}{c}\text { Nkpai } \\
\text { I } \\
\text { L/D }\end{array}$ & & $* ! *$ & & \\
\hline c. $\quad \begin{array}{l}\text { nkpai } \\
\text { V } \\
\text { D L }\end{array}$ & & $* !$ & & \\
\hline $\begin{array}{l}\text { d. mkpai } \\
\text { I I } \\
\text { L D L }\end{array}$ & & $* ! * *$ & & \\
\hline
\end{tabular}

Since we are not dealing yet with cases involving the relevant affixes, the top-ranking constraint * COMPSEG $\mathrm{A}$ does no work here. Candidates (38)b-d all violate Spread to some degree, and so in this simple case (38)a wins, though it violates *COMPSEG (and faithfulness) more than the other candidates do. Three violations of FArTH are counted in (38)a since the nasal both loses its input [labial] specification and gains links to the following [labial] and [dorsal] features. SPREAD is violated three times in (38)d since there are three possible but unachieved feature-segment links in the two-segment consonantal sequence, the only segments we count here (see section 3 for more details on these assumptions).

Things are different when we consider cases involving the relevant affixes, as demonstrated in the next tableau, for the example $/ \mathrm{mi}+\mathrm{kpai} / \rightarrow \eta \mathrm{kpai}$ 'my cheeks'. Here the nasal is genuinely [labial] underlyingly; for simplicity the vowel loss and concomitant syllabicity of this nasal are assumed here. 
(39) Partial NPA across morpheme boundary: 1 -kpai 'my cheeks'

\begin{tabular}{|c|c|c|c|c|}
\hline Input $=/ \mathrm{m}-\mathrm{kpai}$ & ${ }^{*}$ COMPSEG $_{\mathrm{A}}$ & SPREAD & ${ }^{*}$ COMPSEG & FAITH \\
\hline a. $\begin{array}{c}\text { nm-kpai } \\
\backslash / \\
\text { L/D }\end{array}$ & $* !$ & & & \\
\hline 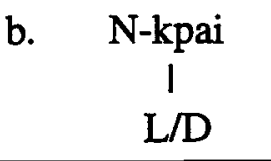 & & $* * !$ & & \\
\hline $\begin{array}{c}\text { c. n-kpai } \\
\text { VI } \\
\text { D L }\end{array}$ & & $*$ & & \\
\hline $\begin{array}{l}\text { d. m-kpai } \\
\text { I I } \\
\text { L D L }\end{array}$ & & $* *$ !* & & \\
\hline
\end{tabular}

(39)a this time is least harmonic, since it violates the top-ranked ${ }^{*} \mathrm{COMPSEG}_{\mathrm{A}}$. Of the remaining three candidates, (39)c is the best, since it respects Spread to the extent allowed by ${ }^{*} \mathrm{COMPSEG}_{\mathrm{A}}$; the extra violations seen in (39)b and (39)d are not forced and therefore not possible.

The Gã case serves to demonstrate that the arguments for FCT seen in section 2.2 still hold given the new assumptions about NPA. Like the earlier hypothetical constraint NPA, SPREAD(PLACE) requires multiple linking of all Place features, and it is demonstrably gradiently violable. ${ }^{20}$

\section{References}

Anderson, John and Colin Ewen. (1987). Principles of Dependency Phonology. Cambridge University Press, Cambridge.

Anderson, Stephen R. (1976). 'On the Description of Multiply-Articulated Consonants'. Journal of Phonetics 4, 17-27.

Archangeli, Diana and Douglas Pulleyblank. (1993). 'Optimality, Grounding Theory, and Rule

Parameters'. Rutgers Optimality Workshop, Rutgers University, New Brunswick, NJ.

Archangeli, Diana and Douglas Pulleyblank. (1994). Grounded Phonology. MIT Press,

Cambridge, MA.

Ashton, E.O., E.M.K. Mulira, E.G.M. Ndawula and A.N. Tucker. (1954). A Luganda Grammar. Longmans, Green and Co., New York.

Bagemihl, Bruce. (1991). 'Syllable Structure in Bella Coola'. LI 22.4, 589-646.

${ }^{20}$ It is possible to envision a more general constraint Spread at work here, requiring features of any class to be maximally linked, so long as other class-specific constraints can curtail the result to place linking as required. Then spreading is perforce less total in Gã. 
Beckman, Jill N. (1995). 'Shona Height Harmony: Markedness and Positional Identity'. Ms., University of Massachusetts, Amherst.

Berry, J. (1951). The Pronunciation of Ga. Heffer, Cambridge.

Bird, Steven. (1995). Computational Phonology: a Constraint-Based Approach. Cambridge University Press, Cambridge.

Bromberger, Sylvain and Morris Halle. (1989). 'Why Phonology is Different'. LI 20.1, 51-70. Browman, Catherine P. and Louis Goldstein. (1986). 'Towards an Articulatory Phonology'.

Phonology Yearbook 3, 219-252.

Browman, Catherine P. and Louis Goldstein. (1989). 'Articulatory Gestures as Phonological Units'. Phonology 6.2, 201-251.

Buckley, Eugene. (1995). 'Constraint Domains in Optimality Theory'. Paper presented at the GLOW Workshop, University of Troms $\varnothing$.

Byrd, Dani. (1992). ". Journal of Phonetics

Cahill, Mike. (1995). 'Nasal Assimilation and Labiovelar Geometry'. Paper presented at ACAL 26.

[Also ms., SIL and Ohio State University, 1994].

Cassimjee, Farida. (1994). 'IsiXhosa Tonology: an Optimal Domains Theory Analysis'. Ms., University of Illinois.

Chesswas, J.D. (1963). The Essentials of Luganda. Oxford University Press, London.

Cho, Young-Mee Yu. (1990). 'A Typology of Voicing Assimilation'. In Aaron Halpern (ed.), Proceedings of the Ninth Annual West Coast Conference on Formal Linguistics, CSLI,

Stanford, 141-155.

Chomsky, Noam and Morris Halle. (1968). The Sound Pattern of English. Harper and Row, New York.

Clements, G.N. (1985). 'The Geometry of Phonological Features'. Phonology Yearbook 2, 22552.

Clements, G.N. (1986). 'Compensatory Lengthening and Consonant Gemination in LuGanda'. In L. Wetzels and E. Sezer, eds., Studies in Compensatory Lengthening. Foris, Dordrecht.

Clements, G.N. (1987). 'Phonological Feature Representation and the Representation of Intrusive Stops'. CLS 23, Part II, Chicago Linguistic Society, 29-50.

Clements, G.N. and Engin Sezer. (1982). 'Vowel and Consonant Disharmony in Turkish'. In Harry v.d. Hulst and Norval Smith, eds., The Structure of Phonological Representations, Part II, Foris, Dordrecht, 213-255.

Cole, Jennifer and Charles W. Kisseberth. (1994). 'An Optimal Domains Theory of Harmony'. Cognitive Science Technical Report UIUC-BI-CS-94-02, University of Illinois, UrbanaChampaign.

Cook, T.L. (1969). The Pronunciation of Efik for Speakers of English. African Studies Program, Bloomington.

Doke, Clement M. (1926). The Phonetics of the Zulu Language. University of the Witwatersrand Press, Johannesburg.

Doke, Clement M. (1931). Text-Book of Zulu Grammar. Longmans, Green and Co., London.

Duanmu, San. (1990). A Formal Study of Syllable, Tone, Stress and Domain in Chinese Languages. Doctoral Dissertation, MTT, Cambridge, MA.

Feinstein, Mark. (1979). 'Prenasalization and Syllable Structure'. LI 10.2, 245-278.

Gazdar, Gerald, Ewen Klein, Geoffrey Pullum and Ivan Sag. (1985). Generalized Phrase Structure Grammar. Harvard University Press, Cambridge, MA. 
Goldsmith, John. (1990). Autosegmental and Metrical Phonology. Basil Blackwell, Cambridge, MA.

Halle, Morris. (1983). 'On Distinctive Features and Their Articulatory Implementation'. NLLT 1, 91-105.

Halle, Morris. (1995). 'Feature Geometry and Feature Spreading'. $L I$ 26.1, 1-46.

Harris, James W. (1969). Spanish Phonology. MIT Press, Cambridge, MA.

Harris, James W. (1984). 'Autosegmental Phonology, Lexical Phonology, and Spanish Nasals'. In

Mark Aronoff and Richard T. Oehrle (eds.), Language Sound Structure, MIT Press,

Cambridge, MA, 67-82.

Hayes, Bruce. (1984). 'The Phonetics and Phonology of Russian Voicing Assimilation'. In Mark Aronoff and Richard T. Oehrle (eds.), Language Sound Structure, MIT Press, Cambridge, MA, 318-328.

Hayes, Bruce. (1990). 'Diphthongisation and Coindexing'. Phonology 7.1, 31-71.

Herbert, R.K. (1975). 'Reanalyzing Prenasalized Consonants'. Studies in African Linguistics 6, 105-123.

Herbert, R.K. (1986). Language Universals, Markedness Theory, and Natural Phonetic Processes. Mouton de Gruyter, New York.

Hoard, J.E. (1978). 'Syllabification in Northwest Indian Languages, with Remarks on the Nature of Syllabic Stops and Affricates'. In A. Bell and J.B. Hooper (eds.), Syllables and Segments, North Holland, Amsterdam.

Itô, Junko. (1986). Syllable Theory in Prosodic Phonology. Doctoral Dissertation, University of Massachusetts, Amherst.

Itô, Junko. (1989). 'A Prosodic Theory of Epenthesis'. NLLT 7.2, 217-259.

Itô, Junko and R. Armin Mester. (1993). 'Licensed Segments and Safe Paths'. In C. Paradis and D. LaCharité (eds.), Constraint-Based Theories in Multilinear Phonology, special issue of the Canadian Journal of Linguistics.

Itô, Junko and R. Armin Mester. (1994). 'Reflections on CodaCond and Alignment'. In Jason Merchant, Rachel Walker and Jaye Padgett, eds., Phonology at Santa Cruz, Linguistics Research Center, UCSC, Santa Cruz, CA.

Itô, Junko and R. Armin Mester. (1995). "The Core-Periphery Structure of the Lexicon and Constraints on Reranking'. In Papers in Optimality Theory, University of Massachusetts Occasional Papers in Linguistics (UMOP) 18, GLSA, UMass, Amherst.

Itô, Junko, R. Armin Mester and Jaye Padgett. (to appear). 'NC: Licensing and Underspecification in Optimality Theory'. $L I$.

Jun, Jongho. (1995). 'Place Assimilation as the Result of Conflicting Perceptual and Articulatory Constraints'. Paper presented at the Fourteenth Annual West Coast Conference on Formal Linguistics.

Kaun, Abigail. (1994). 'An Optimality-Theoretic Account of Rounding Harmony Typology'. Paper presented at the West Coast Conference on Formal Linguistics.

Keating, Patricia. (1988). 'Palatals as Complex Segments: X-ray Evidence'. UCLA Working Papers in Phonetics 69, 77-91.

Kingston, John. (1990). 'Articulatory Binding'. In John Kingston and Mary E. Beckman (eds), Papers in Laboratory Phonology I. Cambridge University Press, 406-434.

Kiparsky, Paul. (1973). '"Elsewhere" in Phonology'. In Stephen R. Anderson and Paul Kiparsky (eds.), A Festschrift for Morris Halle, Holt, Rinehart and Winston, New York, 93-106. 
Kiparsky, Paul. (1982). 'Lexical Phonology and Morphology'. In I.S. Yang (ed.), Linguistics in the Morning Calm, vol. 2, Hanshin, Seoul, 3-91.

Kiparsky, Paul. (1985). 'Some Consequences of Lexical Phonology'. Phonology 2, 85-138.

Kiparsky, Paul. (1993). 'Remarks on Markedness'. Second Trilateral Phonology Weekend, UC Santa Cruz.

Kirchner, Robert. (1993). 'Turkish Vowel Harmony and Disharmony: an Optimality Theoretic Account'. Ms., UCLA, of talk presented at the Rutgers Optimality Workshop I, New Brunswick, NJ.

Kotey, Paul F. Amon. (1974). 'Consonantal Labialization and Consonant Clusters in Ga'. The Journal of West African Languages. 9.1, 49-56.

Kropp, M.E. (1966). 'The Morphology of the Ga Aspect System'. Journal of African Langauges 5.2, 121-127.

Lass, Roger. (1976). English Phonology and Phonology Theory. Cambridge Studies in Linguistics 14, Cambridge University Press.

Lass, Roger and John Anderson. (1975). Old English Phonology. Cambridge Studies in Linguistics 17, Cambridge University Press.

Lombardi, Linda. (1991). Laryngeal Features and Laryngeal Neutralization. Doctoral Dissertation, University of Massachusetts, Amherst. [Published by Garland Press, 1994].

Lombardi, Linda. (1995a). 'Positional Faithfulness and the Phonology of Voicing in Optimality Theory'. Ms., University of Maryland, College Park.

Lombardi, Linda. (1995b). 'Laryngeal Neutralization and Alignment'. In Papers in Optimality Theory, University of Massachusetts Occasional Papers in Linguistics (UMOP) 18, GLSA, UMass, Amherst.

McCarthy, John J. (1988). 'Feature Geometry and Dependency: A Review'. Phonetica 43, 84108.

McCarthy, John J. (1994). 'On Coronal "Transparency"'. Paper presented at the annual Trilateral Phonology Weekend, UC Santa Cruz.

McCarthy, John J. and Alan Prince. (1993a). 'Generalized Alignment'. Ms., University of Massachusetts, Amherst, and Rutgers University, New Brunswick.

McCarthy, John J. and Alan Prince. (1993b). 'Prosodic Morphology I: Constraint Interaction and Satisfaction'. Ms., University of Massachusetts, Amherst, and Rutgers University, New Brunswick.

McCarthy, John J. and Alan Prince. (1995). 'Faithfulness and Reduplicative Identity'. Ms., University of Massachusetts, Amherst and Rutgers University, New Brunswick, NJ.

McCawley, James. (1967). 'The Role of a Phonological Feature System in a Theory of Language'. Languages 8, 112-123.

Maddieson, Ian and Peter Ladefoged. (1989). 'Multiply Articulated Segments and the Feature Hierarchy'. In UCLA Working Papers in Phonetics 72, 116-138.

Mascaró, Joan. (1976). Catalan Phonology and the Phonological Cycle. Doctoral Dissertation, MIT, Cambridge, MA.

Mascaró, Joan. (1983). 'Phonological Levels and Assimilatory Processes'. Ms., Universitat Autònoma de Barcelona.

Mester, R. Armin and Junko Itô. (1989). 'Feature Predictability and Underspecification: Palatal Prosody in Japanese Mimetics'. $\mathrm{Lg}$ 65, 258-293.

Mohanan, K.P. (1983). 'The Structure of the Melody'. Ms., MIT, Cambridge, MA. 
Mohanan, K.P. (1986). The Theory of Lexical Phonology. Reidel, Dordrecht.

Mohanan, K.P. (1991). 'On the Bases of Radical Underspecification'. NLLT 9, 285-325.

Mohanan, K.P. (1993). 'Fields of Attraction in Phonology'. In John Goldsmith (ed.), The Last

Phonological Rule: Reflections on Constraints and Derivations. University of Chicago Press, 61-116.

Ni Chiosáin, Máire. (1995). 'Barra Gaelic Vowel Copy and (Non-)Constituent Spreading'. In Proceedings of WCCFL 13.

Ní Chiosáin, Máire and Jaye Padgett. (1993). 'Inherent VPlace'. Report no. LRC-93-09,

Linguistics Research Center, UC Santa Cruz.

Odden, David. (1991). 'Vowel Geometry'. Phonology 8, 261-90.

Ohala, John J. (1990). 'The Phonetics and Phonology of Aspects of Assimilation'. In John

Kingston and Mary E. Beckman (eds), Papers in Laboratory Phonology I. Cambridge

University Press, 258-275.

Ohala, John J. and James Lorentz. (1977). The Story of [w]: an Exercise in the Phonetic

Explanation for Sound Patterns'. In Proceedings of the 3rd Annual Meeting of the Berkeley

Linguistics Society, BLS, UC Berkeley.

Ohala, John J. and Manjari Ohala. (1993). "The Phonetics of Nasal Phonology: Theorems and

Data'. In Huffman and Krakow (1993), 225-249.

Orgun, Orhan. (1994). 'Monotonic Cyclicity and Optimality Theory'. In proceedings of NELS 24, 461-474.

Padgett, Jaye. (1991). Stricture in Feature Geometry. Doctoral Dissertation, University of Massachusetts, Amherst.

Padgett, Jaye. (1994). 'Stricture and Nasal Place Assimilation'. NLLT 12, 465-513.

Padgett, Jaye. (1995a). 'Feature Classes'. In Papers in Optimality Theory, University of Massachusetts Occasional Papers (UMOP) 18, GLSA, UMass, Amherst.

Padgett, Jaye. (1995b). 'Feature Classes II'. Paper presented at the Holland Institute of Linguistics Phonology Conference, Amsterdam. [Ms. in progress].

Padgett, Jaye (1995c). Stricture in Feature Geometry. CSLI Publications, Stanford, CA.

[Revision of Padgett 1991].

Painter, Colin. (1970). Gonja: a Phonological and Grammatical Study. Indiana University Press, Bloomington.

Paradis, Carole. (1988). 'On Constraints and Repair Strategies'. Linguistic Review 6, 71-97.

Pickett, J.M., H. Timothy Bunnell and Sally G. Revoile. (1995). 'Phonetics of Intervocalic

Consonant Perception: Retrospect and Prospect'. Phonetica 52, 1-40.

Piggott, G.L. (1992). 'Variability in Feature Dependency: the Case of Nasality'. NLLT 10.1, 3377.

Prince, Alan and Paul Smolensky. (1993). 'Optimality Theory: Constraint Interaction in

Generative Grammar'. Ms., Rutgers University, New Brunswick, and University of

Colorado, Boulder.

Pulleyblank, Douglas. (1986). Tone in Lexical Phonology. Reidel, Dordrecht.

Pulleyblank, Douglas. (1994). 'Vowel Harmony in Optimality Theory'. To appear, Proceedings of the Workshop on Phonology, University of Coimbra, Portugal, September 1993.

Recasens, Daniel. (1991). Fonética Descriptiva del Català. Institut D'Estudis Catalans, Biblioteca Filològica XXI, Barcelona. 
Recasens, Daniel. (1993). Fonètica i Fonologia. Biblioteca Universitària 18, Enciclopèdia Catalana, Barcelona.

Reinecke, B. (1972). The Structure of the Nkonya Language. VEB Verlag Enzyklopädie, Leipzig. Ryder, Mary Ellen. (1987). 'An Autosegmental Treatment of Assimilation to Labiovelars'. In proceedings of CLS 23 Part Two: Parasession on Autosegmental and Metrical Phonology, Chicago Linguistic Society.

Sagey, Elizabeth. (1986). The Representation of Features and Relations in Non-Linear Phonology. Doctoral Dissertation, MT, Cambridge, MA.

Sagey, Elizabeth. (1987). 'Non-Constituent Spreading in Barra Gaelic'. Ms., School of Social Sciences, UC Irvine.

Scobbie, James M. (1991). Attribute Value Phonology. Doctoral Dissertation, University of Edinburgh.

Scobbie, James M. (1993). 'Constraint Violation and Conflict from the Perspective of Declarative Phonology'. Canadian Journal of Linguistics 38, 155-167.

Selkirk, Elisabeth. (1982). 'The Syllable'. In Harry van der Hulst and Norval Smith (eds), The Structure of Phonological Representations vol. 2. Foris, Dordrecht, 337-384.

Selkirk, Elisabeth. (1991a). 'Major Place in the Vowel Space. Vowel Height'. Paper presented at the Workshop on Feature Organization, Linguistic Society of America Institute, Santa Cruz, CA. [manuscript University of Massachusetts, Amherst].

Selkirk, Elisabeth. (1991b). 'A Two-Root Theory of Length'. In E. Dunlap and J. Padgett, eds., University of Massachusetts Occasional Papers in Linguistics 14: Papers in Phonology. GLSA, UMass, Amherst.

Selkirk, Elisabeth. (1994). Class notes, Linguistics 730, University of Massachusetts, Amherst.

Skorik, P. 1961. Grammatika Cukotskogo Jazyka. Akademija Nauk, Moscow-Leningrad.

Smolensky, Paul. (1993). 'Optimality, Markedness, and Underspecification'. Paper presented at the Rutgers Optimality Workshop I, New Brunswick, NJ.

Steriade, Donca. (1982). Greek Prosodies and the Nature of Syllabification. Doctoral Dissertation, MT, Cambridge, MA.

Steriade, Donca. (1987). 'Redundant Values'. In Anna Bosch, Barbara Need and Eric Schiller (eds.), Papers from the 23rd Annual Regional Meeting of the Chicago Linguistic Society, Part II, Chicago Linguistic Society, 339-362.

Steriade, Donca. (1993a). 'Closure, Release and Nasal Contours'. in Huffman and Krakow (1993), 401-470.

Steriade, Donca. (1993b). 'Positional Neutralization'. Paper presented at NELS 24.

Steriade, Donca. (1994). 'Complex Onsets as Single Segments: the Mazateco Pattern'. In Jennifer Cole and Charles Kisseberth (eds.), Perspectives in Phonology, CSLI Publications, Stanford, CA, 203-291.

Steriade, Donca. (1995a). 'Underspecification and Markedness'. In John Goldsmith, ed., Handbook of Phonological Theory, Blackwell, Oxford.

Steriade, Donca. (1995b). 'Laryngeal Neutralization and Laryngeal Features'. Paper presented at the Arizona Phonology Conference, University of Arizona, Tuscon.

Trigo, Rosaria Lorenza. (1988). On the Phonological Derivation and Behavior of Nasal Glides. Doctoral Dissertation, MTT, Cambridge, MA.

Welmers, W.E. (1962). 'The Phonology of Kpelle', Journal of African Languages 1, 69-93. 
Zsiga, Elizabeth. (1993). Features, Gestures, and the Temporal Aspects of Phonological Organization. Doctoral Dissertation, Yale University, New Haven, CT.

Department of Linguistics

Stevenson College

UCSC

Santa Cruz, CA 95064

padgett@ling.ucsc.edu 